University of Rhode Island

DigitalCommons@URI

Open Access Dissertations

2013

\title{
Childhood Maltreatment, Posttraumatic Cognitions, and Health Outcomes Among Young Adults
}

Elizabeth Reichert

University of Rhode Island, elizabeth.reichert@gmail.com

Follow this and additional works at: https://digitalcommons.uri.edu/oa_diss

\section{Recommended Citation}

Reichert, Elizabeth, "Childhood Maltreatment, Posttraumatic Cognitions, and Health Outcomes Among Young Adults" (2013). Open Access Dissertations. Paper 14.

https://digitalcommons.uri.edu/oa_diss/14

This Dissertation is brought to you for free and open access by DigitalCommons@URI. It has been accepted for inclusion in Open Access Dissertations by an authorized administrator of DigitalCommons@URI. For more information, please contact digitalcommons-group@uri.edu. 
CHILDHOOD MALTREATMENT, POSTTRAUMATIC COGNITIONS, AND HEALTH OUTCOMES AMONG YOUNG ADULTS

BY

ELIZABETH REICHERT

A DISSERTATION SUBMITTED IN PARTIAL FULFILLMENT OF THE

REQUIREMENTS FOR THE DEGREE OF

DOCTOR OF PHILOSOPHY

IN

CLINICAL PSYCHOLOGY

UNIVERSITY OF RHODE ISLAND 


\section{DOCTOR OF PHILOSOPHY DISSERTATION}

OF

ELIZABETH REICHERT

\section{APPROVED:}

Dissertation Committee:

Major Professor Ellen Flannery-Schroeder

Kat Quina

Tiffani Kisler

Nasser H. Zawia DEAN OF THE GRADUATE SCHOOL

UNIVERSITY OF RHODE ISLAND

2013 


\begin{abstract}
Childhood maltreatment is a significant public health issue that has been linked to a myriad of negative long-term mental and physical health consequences. While the devastating health outcomes have been well established in the literature, the potential mechanisms of this link are less understood. In an effort to elucidate this relationship, the present study examined maladaptive cognitions (i.e., posttraumatic cognitions related to the self and world) that can form as a result of experiencing the trauma of maltreatment. Specifically, this cross-sectional study investigated the association between childhood maltreatment and self-reported mental and physical health concerns among a sample of young adults. Participants were 287 undergraduate students (ages 18-29 years) recruited from a mid-sized northeastern university. Retrospective, self-report questionnaires were used to assess childhood maltreatment, posttraumatic cognitions and current mental and physical health functioning. Data were analyzed using structural equation modeling. Childhood maltreatment was found to be significantly associated with poorer mental and physical health functioning. Support was found for posttraumatic cognitions as mediators in this relationship. Findings provide support for childhood maltreatment as an important risk factor for adverse long-term health outcomes, with posttraumatic cognitions playing an important role in this relationship. Maladaptive cognitions that form as a result of experiencing the trauma of maltreatment may be particularly useful points of intervention in order to mitigate health concerns in adulthood.
\end{abstract}




\section{ACKNOWLEDGMENTS}

I would like to extend my utmost gratitude to my major professor, Dr. Ellen Flannery-Schroeder for her tremendous mentorship, support, and guidance throughout my graduate school training. For nearly five years, Dr. Flannery-Schroeder has continuously provided me with guidance in all areas of my professional development. She has served as my mentor, my professor, my supervisor and friend, and in these various capacities has played a substantial role in developing this line of research. Her expertise, patience and unwavering support over the years and especially with this project were unparalleled and I am deeply indebted to her. I would also like to extend my sincerest gratitude to my entire dissertation committee, Dr. Kat Quina, Dr. Tiffani Kisler, Dr. Mark Robbins, and Dr. Furong Xu for their valuable input, feedback, and encouragement. In addition, I would like to thank Steve Babbin, M.A., for his methodological expertise, patience and support with this project. Lastly, I am genuinely grateful to my parents, Leslie and Michel Reichert, my brother, Alexander, and to my fellow graduate student peers who have provided me with unconditional and consistent moral support and encouragement as I worked on this project. 


\section{TABLE OF CONTENTS}

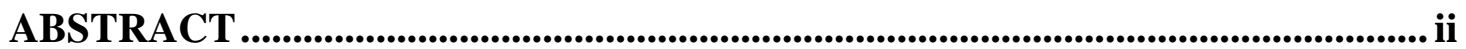

ACKNOWLEDGMENTS .................................................................................................... iii

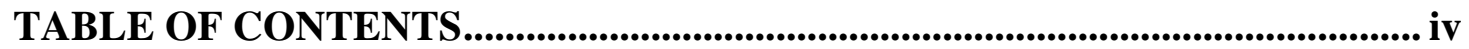

LIST OF TABLES ............................................................................................................... v v

LIST OF FIGURES ................................................................................................................ vi

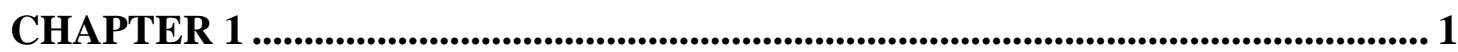

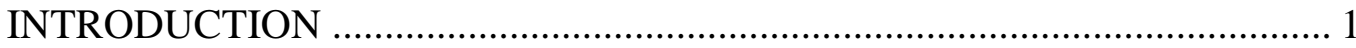

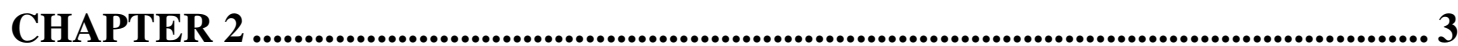

REVIEW OF LITERATURE …………………………........................... 3

CHAPTER 3 ............................................................................................................................... 19

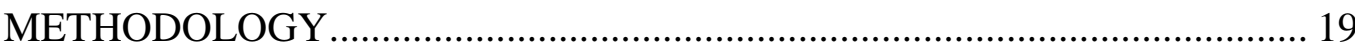

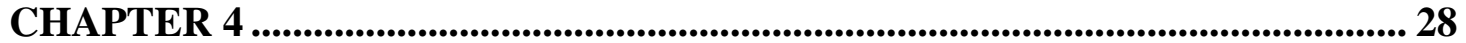

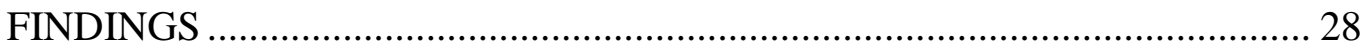

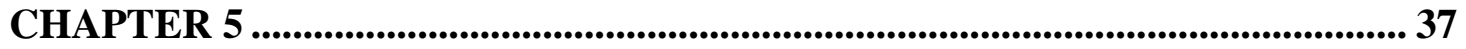

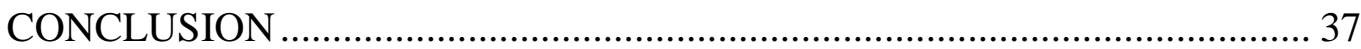

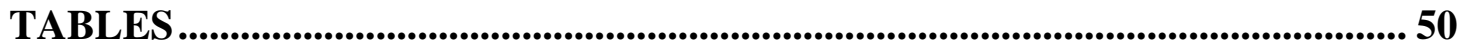

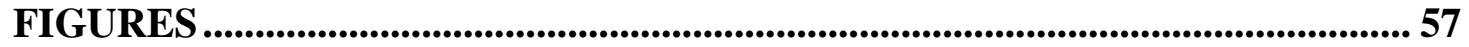

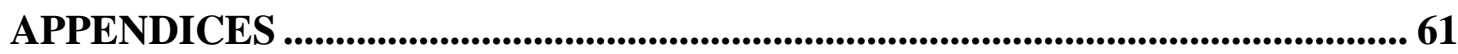

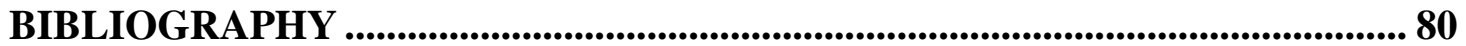




\section{LIST OF TABLES}

TABLE

PAGE

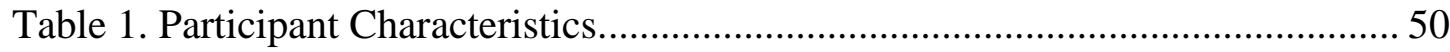

Table 2. Means, Standard Deviations, and Observed Ranges for Scores on the CTQ,

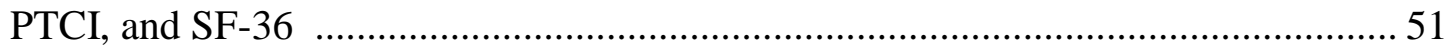

Table 3. Rates of Different Forms of Maltreatment Endorsed Among Participants...52

Table 4. Comparison of Participants with Current PTSD-symptomatology and

Participants Without PTSD-Symptomatology on the CTQ, PTCI, and SF-36 .........53

Table 5. Standard Multiple Regression of Different Types of Childhood Maltreatment

Predicting Posttraumatic Cognitions ..............................................54

Table 6. Standard Multiple Regression of Different Types of Childhood Maltreatment

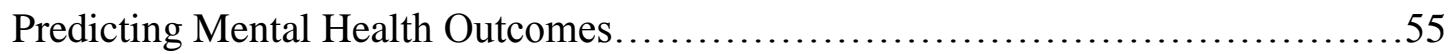

Table 7. Standard Multiple Regression of Different Types of Childhood Maltreatment

Predicting Physical Health Outcomes..........................................56 


\section{LIST OF FIGURES}

FIGURE

PAGE

Figure 1. Proposed Mediational Model.................................................................. 57

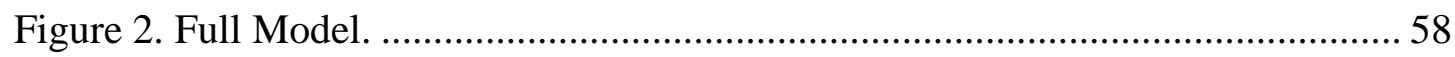

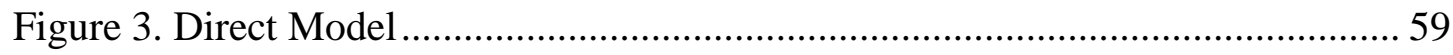

Figure 4. Modified Mediational Model and Standardized Solution ............................. 60 


\section{CHAPTER 1}

\section{INTRODUCTION}

Childhood maltreatment is a pervasive problem rendering not only a major public health issue but also a myriad of negative health consequences for victimized children throughout their lives. Extensive research on the effects of childhood maltreatment has identified a wide range of negative sequelae, with particular attention to poorer long term mental and physical health outcomes (e.g., Briere \& Elliot, 2003; WHO, 2006). According to a recent report, the World Health Organization (WHO, 2006) declared childhood maltreatment to be associated with a range of health risk behaviors, directly contributing to some of the leading causes of death and chronic disease. Furthermore, while the actual physical injury associated with the traumatic event may be painful and cause harm to the child at the time of the event, the psychological consequences, longterm neurological, cognitive, and emotional development and overall health of the child are at risk for to be severely impacted as well (WHO, 2006). As a result, childhood maltreatment may be a significant etiological factor in the development and maintenance of health problems later in life.

The World Health Organization (WHO, 2006) distinguishes four types of childhood maltreatment that may occur before the age of 18: physical abuse, sexual abuse, emotional abuse, and neglect (i.e., physical and/or emotional). While childhood maltreatment is responsible for thousands of deaths each year, millions are also victims of non-fatal abuse and neglect (WHO, 2006). Those who are victims of 
childhood maltreatment, if untreated, are at high risk for developing poorer mental and physical health outcomes. As such, childhood maltreatment is a problem that touches communities worldwide, contributing to devastating health consequences.

Despite a clear link between childhood maltreatment and poorer overall health in adulthood, there is a surprisingly limited understanding of the intervening variables affecting this relationship. As such, an imperative next step is to examine these relationships to inform critical prevention and treatment efforts to reduce the prevalence and devastating effects of childhood maltreatment. 


\section{CHAPTER 2}

\section{REVIEW OF LITERATURE}

Childhood maltreatment is a large-scale problem that places a significant burden on the both the individual and the healthcare system. The effects of maltreatment can be immediate, but perhaps most importantly, can produce significant short-term and long-term sequelae (Buckingham \& Daniolos, 2013). While the prevalence and total impact of childhood maltreatment is often difficult to determine due to underreporting and misdiagnosis, estimates based on confirmed cases of maltreatment point to an annual healthcare cost of 124 billion dollars in the United States alone (Buckingham \& Daniolos, 2013; Fang, Brown, Florence, Mercy, 2012; Martin, Volkmar, \& Lewis, 2007).

Prevalence rates of early maltreatment vary due to a number of complicating factors including, methodological issues (e.g., inconsistency in study design, definition of terms, study population, assessment measures), unreported or underreported cases, misdiagnosis (e.g., classified as another form of injury), and differing legal standards

for substantiating maltreatment (Arnow, 2004; Buckingham \& Daniolos, 2013; Macdonald, 2007; Rosenberg \& Krugman, 1991; US Government Accountability Office, 2011). Despite these factors, documented prevalence rates are alarmingly high. For example, in a community sample, researchers found that $37 \%$ of all respondents reported a history of either sexual or physical abuse before age 18 and approximately $21 \%$ of these respondents reported instances of both physical and sexual abuse (Briere 
$\&$ Elliot, 2003). In a primary care sample of adults, $44 \%$ reported a history of abuse during childhood (i.e., physical, sexual or emotional abuse) and 22\% reported multiple forms of abuse (Gould et al., 1994). As may be expected, within a clinical sample, the highest rates of childhood maltreatment were reported (Briere, Woo, McRae, Foltz, Sitzman, 1997). According to the US Administration on Children and Families (2009), 3.3 million claims of maltreatment occur per year in the US and approximately $30 \%$ of these claims are substantiated. It is important to note that these statistics are likely an underestimation of actual prevalence rates, suggesting that even higher rates of maltreatment may exist. Consequently, the true prevalence of childhood maltreatment remains difficult to determine (Hussey, Change, \& Kotch, 2006).

Keeping in mind the alarming rates of maltreatment, current findings suggest some differences in prevalence among men and women (e.g., Briere \& Elliot, 2003; Finkelhor, 1994; Gould et al., 1994; Walker et al., 1999). For instance, females have been found to report more sexual abuse, emotional abuse, and multiple forms of abuse when compared to men (Miller, Green, Fettes, \& Aarons, 2011). Consistent with these findings, a study examining undergraduates found that females reported more emotional abuse and sexual abuse than males (Paivio \& Ramer, 2004). Evidence for gender differences in other forms of maltreatment, however, is mixed (Edwards, Holden, Felitti, \& Anda, 2003; Miller et al., 2011; USDHHS, 2005).

The potential for multiple traumatic events during a child's life are far more likely to occur than a single instance of trauma (e.g., Felitti et al., 1998). Experiencing one form of childhood maltreatment increases the likelihood of experiencing other types of maltreatment, with approximately an 80 percent chance of experiencing 
another form of trauma in one's lifetime (Feltti et al., 1998). Studies considering the co-occurrence of physical, emotional and sexual abuse have found low prevalence rates (less than $10 \%$ ) for single types of maltreatment, while the majority of victimized children are found to be victims of multiple forms of abuse (McGee, Wolfe, Yuen, Wilson, \& Carnochan, 1995). Finally, evidence for racial and ethnic differences in the prevalence of child maltreatment has been found; however, findings are confounded by issues related to socioeconomic status and education level (Scher, Forde, McQuaid, \& Stein, 2004).

\section{Adult Mental Health Outcomes}

Childhood maltreatment has serious implications for the emotional and psychosocial well-being of a child far into adulthood (Gilbert et al., 2009). During childhood and adolescence, childhood maltreatment is linked to increased risks of psychological and behavioral problems (e.g., anxiety, depression, aggression, and acting out) (e.g., Fergusson, Boden, \& Horwood, 2008). In adulthood, maltreated children are at an increased risk of developing even greater, and often more severe, psychological problems (e.g., major depressive disorder, PTSD, eating disorders, personality disorders) (e.g., Arnow, 2004; Banyard et al., 2001; Fergusson et al., 2008; Goodwin, Fergusson, \& Horwood, 2005; Kendler et al., 2000; Molnar, Buka, \& Kessler, 2001; Tarquis, 2006; Tyrka, Wyche, Kelly, Price, \& Carpenter, 2009; Widom, White, Czaja, \& Marmorstein, 2007; Smyth, Heron, Wonderlich, Croby, \& Thomson, 2008). Research suggests that childhood maltreatment is also linked to additional psychological sequelae in adulthood (e.g., low self-esteem, anger, 
aggression, sexual difficulties, self-injurious or self-destructive behaviors) (see Briere \& Elliot, 2003; Neumann, Houskamp, Pollack, \& Briere, 1996 for reviews).

The relationship between childhood maltreatment and poor mental health has been well established using clinical populations (e.g., Brown \& Anderson, 1991; McCauley, Kern, Kolodner, Dill, \& Schroeder, 1997) as well as community and population-based samples (e.g., Jumper, 1995; Neumann, Houskamp, Pollack, \& Briere, 1996). Edwards and colleagues (2003) studied the effect of the co-occurrence of multiple forms of maltreatment (e.g., physical/sexual abuse, neglect) on psychological health among a sample of adult patients in an $\mathrm{HMO}(\mathrm{N}=8,677)$. Specifically, this study examined prevalence of various combinations of types of childhood maltreatment and explored whether the relationship between number of traumas and psychopathology was further impacted by emotional abuse in the childhood family environment. Results indicated that $34.6 \%$ of participants reported more than one type of trauma. A dose-response relationship between the number of indicators of childhood maltreatment and overall mental health scores was also supported, and the relationship between the number of traumas and poorer mental health was further strengthened by reports of an emotionally abusive family environment. Consistently, this type of graded relationship between number of traumatic experiences during childhood and poorer mental health outcomes in adulthood has been found (Mullen, Martin, Anderson, Romans, \& Herbison, 1996; Felitti et al., 1998). In addition, gender differences are supported. Notably, males with a history of physical abuse were found to report more externalizing disorders in adulthood, whereas females tend to report more internalizing disorders, suggesting 
gender-specific consequences for the expression of psychiatric disorders (Keyes et al., 2012).

\section{Adult Physical Health Outcomes}

A growing body of literature suggests that childhood maltreatment can lead to poor physical health outcomes in adulthood. Adults who report a history of childhood maltreatment tend to have greater physical problems (both medically explained and unexplained) and tend to exhibit more high-risk health behaviors than individuals without a history of maltreatment (Walker et al., 1999; Felitti et al., 1998). Specifically, links between childhood maltreatment and increased rates of medical problems, health risk behaviors, poorer self-rated health, and higher rates of health care utilization have been well-documented (e.g., Chartier, 2007; Chartier, Walker, \& Naimark, 2009; Davis, Luecken, \& Zautra, 2005; Felitti et al., 1998; Sachs-Ericsson, Blazer, Plant, \& Arnow, 2005; Walker al., 1999; Newman et al., 2000; Finestone et al., 2000; McCauley et al., 1997). Medical problems often include conditions such as physician-diagnosed disease and chronic illness (e.g., gastrointestinal problems, diabetes, obesity), pain symptoms, somatic concerns, and functional disability (Kendall-Tackett \& Marshall, 1999; Kendall-Tacket, 2000; Lampe et al., 2003; Drossman et al., 1990; Williamson, Thomson, Anda, Dietz, \& Felitti, 2002). For women in particular, a history of child maltreatment is associated with gynecological problems, headaches, arthritis, and breast cancer (Golding, 1994; 1999; Stein \& Barret-Conner, 2000) and for men, thyroid disease (Stein \& Barret-Conner, 2000). Furthermore, studies have found childhood sexual and physical abuse to be associated with the one-year prevalence of serious health problems in adulthood (e.g., 
autoimmune diseases, arthritis, asthma, heart problems) (Sachs-Ericsson, Blazer, Plant, \& Arnow, 2005; Sachs-Ericsson, Kendall-Tackett, \& Hernandez, 2007). Perhaps most notably, such health concerns are some of the most common causes of death and disability in the United States (Felitti et al., 1998; White \& Widom, 2003). Survivors of childhood maltreatment have been found to be more likely to engage in risky health-related behaviors, and such behaviors may be precipitants or contributors to increased medical problems (Felitti et al., 1998; Walker, 1999; Chartier, Walker, \& Naimark, 2009). In two separate studies, for example, women with a history of sexual abuse versus those without were found to report a greater number of health risk behaviors such as having multiple sexual partners, exchanging sex for drugs or money, using alcohol and drugs, and smoking (Coker, Smith, Bethea, King, \& McKeown, 2000; Young \& Katz, 1998). Similarly, additional studies have found that childhood abuse was significantly associated with several adverse physical health outcomes, including poorer perceived overall health, greater physical and emotional functional disability, increased numbers of distressing physical symptoms, and a greater number of health risk behaviors (e.g., Chartier, et al., 2009; Walker et al., 1999). This association was even stronger among females reporting a history of multiple forms of maltreatment. Felitti and colleagues (1998) suggest that an increase in health-risk behaviors might be related to using such behaviors (e.g., alcohol/drug use) as coping devices. Furthermore, a dose-response relationship between the number of instances of childhood maltreatment and the severity of negative adult physical health outcomes has been demonstrated, suggesting an additive effect of maltreatment (e.g., Arnow, Hart, Hayward, Dea, O’Connell, \& Taylor, 1999; Felitti et al., 1998; 
Golding, Cooper, \& George, 1997; Kessler, Davis, \& Kendler, 1997; Sachs-Ericsson, Cromer, Hernandez, \& Kendall-Tackett, 2009).

\section{Health Care Utilization}

As might be expected, childhood maltreatment has been identified as a key factor in predicting greater use of health care services (e.g., Chartier, Walker, \& Naimark, 2010; Arnow et al., 1999; Yanos, Czaja, \& Windom, 2010; Finestone et al., 2000; Newman et al., 2000; Walker et al., 1999). Studies of adult women with histories of child abuse, for instance, were found to report more annual primary care visits and have greater health care costs than individuals without histories of maltreatment (Arnow et al., 1999; Hulme, 2000; Walker et al., 1999). Similarly, significantly higher annual health care utilization and costs were found for women with history of child sexual and/or physical abuse; annual health care costs were $16 \%$ higher for women with sexual abuse only, 22\% higher for women with physical abuse only and 36\% higher for women with both types of abuse (Bonomi et al., 2008). Thus, childhood abuses are associated with long-term enhanced health care use and costs (Sarkar, 2010).

The relationship between maltreatment and higher rates of health care utilization may be best explained by this population's more significant psychopathology (Kessler, Sonnega, Bromet, Hughes, \& Nelson, 1995) and increased medical comorbidity (Beckham et al., 1998; Elhai, North, \& Frueh, 2005; Brown, Stout \& Meuller, 1999). Population-based research has provided support for such findings (e.g., Chartier, Walker, \& Naimark, 2009; 2010; Yanos, Czaja, \& Widom, 2010). Similarly, young adults with a history of childhood maltreatment use 
significantly more health services compared to those with no history (Yanos, Czaja, \& Widom, 2010).

Arnow et al. (1999) assessed the relationship between childhood sexual abuse, psychological distress and medical health care utilization in a sample of 208 adult women drawn from a health maintenance organization's (HMO) computerized database. Service utilization included non-psychiatric outpatient visits, emergency room (ER) visits, inpatient admissions, and outpatient psychiatric visits. Utilization rates were found to be higher among victims of abuse when compared to controls, with visits to the ER as the most significant difference, and were further increased by the presence of psychological distress. Similarly, in a study of 608 women participating in an HMO, Newman and colleagues (2000) asked participants to provide retrospective reports of the number of visits to a variety of health care providers over the past year. For a subset of these participants $(\mathrm{N}=136)$, researchers obtained access to participants' electronic HMO records which provided objective data for all outpatient and inpatient visits to all sites covered by the HMO. Individuals with a history of abuse were found to report significantly more doctors' visits than non-abused counterparts, with differences between groups on the objective measures following the same pattern. Interestingly, the study found only moderate correlations between self-report and the objective measures with a tendency to underreport service use (Newman et al., 2000).

\section{Posttraumatic Cognitions}

While rates of childhood maltreatment are disturbingly high and clearly associated with significantly poorer health outcomes, not all child victims go on to 
develop negative sequelae, raising the question of "why?" There is a limited understanding of the actual mechanisms that link childhood maltreatment to poorer overall health (e.g., Kendall-Tackett, 2003; Sachs-Ericsson, Cromer, Hernandez, Kendall-Tackett, 2009; Davis, Combs-Lane \& Smith, 2004). In accordance with Foa and colleagues' emotional processing theory (Foa \& Riggs, 1993; Foa, Steketee \& Rothbaum, 1989), one pathway through which childhood maltreatment may lead to negative health is via the cognitions that form after experiencing maltreatment.

The emotional processing theory was developed to explain the development and maintenance of posttraumatic stress disorder (PTSD). This theory states that the relationship between trauma and PTSD is mediated by beliefs that the world is completely dangerous (belief about world) and that the self is completely incompetent (belief about self) and thus, PTSD is a result of a disruption in the "normal processes of recovery" (p. 303, Foa, Ehlers, Clarke, Tolin, \& Orsillo, 1999). According to Foa and Rothbaum (1998), individuals may acquire these dysfunctional cognitions (i.e., “posttraumatic cognitions") one of two ways. On one hand, individuals may enter into the traumatic experience with rigid beliefs about the world being extremely safe and the self extremely competent, and thus, they have significant difficulty incorporating the traumatic experience into existing schemas. On the other hand, the event may act as a primer for pre-existing schemas of the world as dangerous place and the self as incompetent, especially among those who have experienced ongoing maltreatment. It is these individuals who are believed to be more vulnerable to developing PTSD. As such, individuals with less rigid concepts about the self and world may be more likely 
to acknowledge the maltreatment as a unique experience and less likely to develop PSTD.

Based on the emotional processing theory, the experience of maltreatment during childhood can impact victims' thoughts and beliefs by activating pre-existing negative schemas or by making it difficult to comprehend such a negative experience within a more rigid set of beliefs (e.g., Ehlers \& Clarke, 2000; Foa \& Riggs, 1993; Foa \& Rothbaum, 1998; Foa, Ehlers, Clarke, Tolin, \& Orsillo, 1999; Fraizer, 2003). As a result, the psychological effects related to childhood maltreatment may begin with cognitive distortions about the self and world that form after the event and then become incorporated into an individual's schemas at an early age (Smucker, Dancu, Foa, \& Niederee, 2002). Since schemas are thought to develop from interactions within one's environment and then guide how individuals attend to and interpret their environment, a trauma during childhood could have a major impact on one's schema (Beck, 1967, 1987; Kovacs \& Beck, 1978). Consequently, the role of the cognitive pathway, in which trauma-related cognitions may augment long-term symptomatology, has received increasing attention among researchers (e.g., Foa, Steketee, \& Rothbaum, 1989; Foa \& Riggs, 1993; McCann \& Pearlman, 1990; Dunmore, Clark \& Ehlers et al., 1999).

While the literature supports posttraumatic cognitions as a mediator in the relationship between traumatic experiences and PTSD, not all trauma victims go on to develop PTSD (e.g., Taft, Stern, King, \& King, 1999; Wagner et al., 2000). In fact, one study found that while $90 \%$ of youth seen in a primary care clinic reported trauma exposure, only $25 \%$ met full or partial PTSD criteria (Lipschitz et al., 2000). A recent 
review of the research on children exposed to trauma found wide ranges in rates of PTSD among survivors of childhood maltreatment, noting studies found between 20 to $63 \%$ of survivors who met full criteria for PTSD (Gabbay, Oatis, Silva, \& Hirsch, 2004). Therefore, it is possible that an individual's interpretation or appraisal of the traumatic event and its sequelae may play an important part in the development of subsequent psychopathology, not limited to PTSD (Foa et al., 1999; Elhers \& Clarke, 2000). Posttraumatic cognitions may act to either buffer the negative effects of maltreatment or to prevent healthy coping (Foa \& Rothbaum, 1998). While posttraumatic stress symptoms remain the most prevalent outcome for trauma survivors who experience cognitive distortions (Brewin \& Holmes, 2003; Ehlers \& Clark, 2000), dysfunctional cognitions are also highly associated with depressive symptoms (Coyne \& Gotlib, 1983) and somatization symptoms (Rief, Hiller, \& Margraf, 1998) in trauma survivors. Furthermore, such cognitions have been found to dramatically increase survivors' risk for disease and lead to poorer overall health (Kendall-Tackett \& Klest, 2010).

Few extant studies have examined the long-term impact of posttraumatic cognitions among victims of childhood maltreatment (Gibb et al., 2001). Briere (2002) noted that one of the "earliest impacts of abuse and neglect is thought to be on the child's internal representations of self and other" (p.2). As a result, children who experience maltreatment tend to develop more negative views of self and others in the context of their maltreatment experience as compared to children who have not been victims of maltreatment (e.g., Allen \& Tarnowski, 1989; Briere, 2002; Ponce, Williams, \& Allen, 2004). In line with the emotional processing theory, these negative 
cognitions often include beliefs that the individual is "intrinsically unacceptable" or "deserving of such punishment or neglect" or may come to view him/herself as "helpless, inadequate, or weak" (Briere, 2002, p. 2). Furthermore, adults with a history of childhood maltreatment tend to report more negative cognitions as compared to those without a history of maltreatment (Gibb et al., 2001; Gold, 1986; Wenninger \& Ehlers, 1998).

Some researchers have suggested that dysfunctional cognitions forming after childhood maltreatment may mediate the relationship between maltreatment and adult depression (Gibb et al., 2001). Using a college sample of men and women $(\mathrm{N}=297)$, Gibb et al. (2001) studied the relationship between a self-reported history of childhood emotional, physical, and sexual abuse, attributional style, cognitions about one's self and the world, and depression over a two and a half year period. Dysfunctional cognitive style was supported as a mediator in the relationship between emotional abuse and depression. Kaysen and colleagues (2005) extended these findings by investigating the mediating role of dysfunctional cognitions in a sample of recently victimized women $(\mathrm{N}=206)$ with a history of child abuse. Similar to findings by Gibb et al. (2001), results supported the hypothesis that dysfunctional beliefs about one's self and others mediated the relationship between childhood maltreatment and adult depression. The relationships between childhood sexual abuse and physical abuse and depression in adulthood were both found to be mediated by dysfunctional cognitions about the world.

Furthermore, individuals' cognitive responses to early traumatic experiences and abilities to self-regulate emotions are thought to be important intervening 
variables though which early abuse contributes to physical health outcomes (e.g., Hagar \& Runtz, 2012; Repetti, Taylor, \& Seeman, 2002; Schnurr \& Green, 2004). While no studies to date have investigated the direct link between posttraumatic cognitions and poorer physical health, support for perceived stress and emotionfocused coping styles as partial mediators in the relationship between childhood maltreatment and adult physical health has been found (e.g., Hagar \& Runtz, 2012). Such findings suggest that survivors of childhood maltreatment tend to engage in emotion-focused coping strategies (e.g., efforts to manage internal experiences) (Hagar \& Runtz). It is likely that these efforts at emotional coping are related to cognitions forming as a result of the maltreatment, as such coping strategies are typically in response to increased stress and emotional dysregulation post-trauma (Hagar \& Runtz). In addition, thoughts related to poor self-esteem and selfcompetence have received some support in the literature as being related to poorer health, adding further support for the effect cognitions can have on one's health functioning (e.g., Benyamini, Leventhal \& Leventhal, 2004; Ma'kikan-gas, Kinnuen, \& Feldt, 2004).

Taken together, research studies indicate that the relationship between childhood maltreatment and poorer health-related outcomes is complex and suggests that maltreatment alone does not account for the variance in health outcomes. It is therefore important to consider mediating variables that may help to elucidate the well-established link between childhood maltreatment and the onset of mental and physical health problems. Cognitions forming after the experience of childhood maltreatment (i.e., "posttraumatic cognitions," "dysfunctional cognitions," or "trauma- 
related" cognitions), may play a role in future health outcomes. Thus, posttraumatic cognitions may be particularly relevant to understanding the relationship between childhood maltreatment and overall poorer mental and physical health in adulthood.

Clearly, experiencing maltreatment during childhood can have long-lasting effects on one's mental and physical health. As one might expect, the rates of health care utilization are also higher among this population when compared to those without a history of childhood maltreatment. Furthermore, the co-occurrence of multiple types of maltreatment makes it difficult to differentiate the effects of one type of maltreatment from another and a single occurrence of maltreatment is less likely than multiple instances (Finkelhor, Ormrod, Turner, \& Hamby, 2005). Given the high rates of co-occurrence, studies focusing on only one form of maltreatment may overestimate its impact on long-term outcomes and obscure the effects of other forms of victimization (Hager \& Runtz, 2012). Posttraumatic cognitions may be critical to understanding the effects maltreatment can have on poorer overall health and increased rates of health care utilization. However, to date, most of the research in this area is limited to the link between posttraumatic cognitions and the development and maintenance of PTSD.

In an effort to address gaps in the literature, the current study examined posttraumatic cognitions as a mediator in the relationship between childhood maltreatment and a broad set of health outcomes not limited to PTSD. In addition, this study examined this relationship in young adults with histories of childhood maltreatment whereas most of the literature has focused on older populations (i.e., middle to later adulthood). Specifically, this study examined whether posttraumatic 
cognitions mediate the relationship between childhood maltreatment and mental and physical health and rates of health care utilization (herein referred to as "Health Outcomes" for simplicity). Childhood maltreatment was examined as the independent variable and health outcomes (i.e., mental health, physical health, healthcare utilization) as dependent variables. Posttraumatic cognitions were evaluated as mediating variables.

Since the literature is suggestive of possible gender differences in type and frequency of maltreatment, as well as differences in mental and physical health outcomes, gender was initially considered as a moderator of this relationship. Similarly, due to the due to the link between childhood maltreatment, posttraumatic cognitions, and the onset of PTSD, current PTSD symptomatology was also originally considered as a moderator. It would follow that the strength of the meditating effect of posttraumatic cognitions on childhood maltreatment-health outcomes link would depend on the presence or absence of current PTSD-symptomatology and gender. However, due to limited sample size (see Results section for details), specific hypotheses regarding moderators could not be evaluated in the current study.

\section{Hypotheses}

This study aimed to test several models of relationships, including a mediation model, in a non-clinical sample of 287 college students. Specifically, the current study investigated the following hypotheses:

1. Childhood maltreatment is a predictor of poorer mental and physical health functioning.

2. Childhood maltreatment is a predictor of more negative posttraumatic cognitions. 
3. More negative posttraumatic cognitions are related to poorer health outcomes (i.e., poorer mental/physical health functioning).

4. A mediational model will provide the best and most parsimonious fit to the data when comparing the following models (see Figures 1, 2, \& 3):

1a. Model A (Full Model) specifies that childhood maltreatment is related both directly and indirectly to mental and physical health variables. It is hypothesized that the fully saturated model will provide a good fit to the data.

1b. Model B (Mediational Model) specifies that the relationships between childhood maltreatment and mental and physical health variables are indirect and mediated by posttraumatic cognitions. It is hypothesized that this model will be the most parsimonious model and provide the best fit to the data.

1c. Model C (Direct Model) specifies that the relationships between childhood maltreatment and mental and physical health outcomes are direct and not mediated by posttraumatic cognitions. It is hypothesized that the direct effects model will be least appropriate for both health outcomes. 


\section{CHAPTER 3}

\section{METHODOLOGY}

\section{Participants}

Participants for the present study were drawn from a sample of 642 (158 males, 475 females and nine who did not report gender) college students. Since the current study intended to examine the relationships between childhood maltreatment, posttraumatic cognitions and health outcomes, only participants who endorsed a history of childhood trauma were included in the analyses described below. Of the 642 participants who completed the survey, 287 endorsed experiencing one or more types of childhood maltreatment (e.g., sexual, physical or emotional abuse, physical or emotional neglect) of at least "low to moderate" severity as determined by the Childhood Trauma Questionnaire (Bernstein \& Fink, 1998). This sample consisted of 72 men $(25.1 \%)$ and 215 women $(74.9 \%)$ with an average age of $19.9(S D=2.4)$. Participation was distributed among grade levels; $36.9 \%$ were freshman, $32.1 \%$ were sophomores, $18.5 \%$ were juniors, $10.8 \%$ were seniors and $1.7 \%$ did not report their year of education. The majority of participants were White $(82.2 \%)$, while $4.9 \%$ were Black/African American, 4.5\% were Asian, 11.8\% identified as Hispanic/Latino, and $8.4 \%$ did not report their race/ethnicity. Most of the participants were unmarried (95.8\%), over half (54\%) lived on campus and nearly all had health insurance $(91.3 \%)$. About a third of the participants (34.5\%) indicated a family history of mental health problems, whereas over half $(53.3 \%)$ reported a family history of physical health 
problems. Participants were required to be at least 18 years old to participate in the study. See Table 1 for demographic characteristics.

\section{Procedure}

The study was approved by the Institutional Review Board (IRB) of the University of Rhode Island (IRB \#HU1112-084). Participants were recruited from 100-level and 200-level courses (e.g., Introduction to Biology) during the Spring 2012 semester. Instructors were contacted and provided with information about the study. Methods of recruitment varied based on instructors' preferences (e.g., attending class meetings to make an announcement, emailing enrolled students). Students who were at least 18 years old were eligible to participate.

Interested students were provided with a description of the study and a URL link to a secure and confidential online consent form via the online survey company, SurveyMonkey (www.surveymonkey.com). Participants were asked to read the consent form and click "yes" if they were willing to participate. If yes, participants were asked to complete a series of questionnaires. Due to SurveyMonkey's encryption software, participants' answers were never linked to any identifying information. The website remained accessible until the optimum sample size was reached. Participants were able to access the website from any computer at any time during data collection. Participants were given the option to skip questions at any time. The survey took approximately 30-45 minutes to complete. At the end of data collection, the data was exported to the principle investigator's password-protected computer as an excel database. 
Participants who completed the survey were eligible to be entered into a drawing for variety of gift cards (ranging from $\$ 10$ to $\$ 50$ ) by clicking on a link to a separate, secure online database and providing his or her email address. Study participation was voluntary and participants were given the investigator's contact information and encouraged to ask questions throughout the study. Participants were also allowed to withdraw from participation at any time.

\section{Measures}

Demographics. Participants were asked to complete a demographics questionnaire. Standard demographic information was requested from participants, including sex, age, race/ethnicity, and information about income, occupation, and education. Questions regarding participants' family demographic information were also asked including parents' highest level of education, family income, and family health history. Participants were also asked whether they currently had health insurance, and if yes, if it was the student health insurance package provided from URI.

Childhood Maltreatment. Participants were asked to complete a childhood maltreatment measure, the Childhood Trauma Questionnaire (CTQ; Bernstein \& Fink, 1998). The CTQ is a frequently used, reliable, and valid measure of maltreatment history (Bernstein et al., 2003). The CTQ is a retrospective, self-report instrument comprised of 28 items that assess five areas of childhood maltreatment using five subscales: Physical Abuse, Emotional Abuse, Sexual Abuse, Physical Neglect, and Emotional Neglect. Each item begins, “When I was growing up.” Participants rate agreement with each item on a five-point Likert-type scale, where " 1 " represents never true for me and " 5 " represents very often true for me, according to the frequency with 
which the experiences occurred. With five items per subscale, scores range from 5-25 for each subscale.

The CTQ subscales, as well as the entire scale, have high test-retest reliability $(r=.80-.88)$ and high levels of internal consistency (Cronbach's $\alpha=.79-.94)$. In the current study, the Cronbach alpha coefficient was .89. Validation studies support the CTQ's convergent and discriminant validity with structured interviews and corroboration with independent data. The CTQ has been used in studies of healthcare use and costs of primary care (Walker et al., 1999; Wright et al., 2001).

Subscale scores on each of the five subtests serve as indicators of childhood maltreatment. Cutoff scores for none to low, low to moderate, moderate to severe, and severe to extreme exposure are provided for each scale (Bernstein and Fink, 1998). According to Bernstein and Fink (1998), these ranges were based on data from a nonclinical sample and were appropriate in identifying "cases" of specific types of abuse and neglect, while using therapist interview ratings for comparison. For the purposes of this study, the lowest level cutoff scores (i.e., low to moderate cutoff scores) for each subscale were used. Participants who endorsed at least low to moderate scores for one or more subscales of maltreatment were considered "positive" for a history of childhood maltreatment and retained for analyses. Cutoff scores were 9 or higher for emotional abuse, 8 or higher for physical abuse, 6 or higher for sexual abuse, 10 or higher for emotional neglect, and 8 or higher for physical neglect. A composite score was computed by summing subscale scores to serve as an indicator for childhood maltreatment. 
Posttraumatic Cognitions. Participants completed a measure of posttraumatic cognitions, The Posttraumatic Cognitions Inventory (PTCI; Foa, Ehlers, Clark, Tolin, \& Orsillo, 1999). The PTCI is a 36-item self-report measure with three subscales that assess for cognitions (i.e., beliefs about self and others) that can form as a result of experiencing a trauma. The measure is comprised of three subscales: negative cognitions about self (PTCI-Self, 21 items), negative cognitions about the world (PTCI-World, 7 items), and self-blame (PTCI-Blame, 5 items). For those participants who had reported a history of childhood maltreatment, participants were ask to rate the occurrence of thoughts and beliefs by indicating the degree to which they "agree" or "disagree" with each statement using a seven-point Likert scale ranging from 1 (totally disagree) to 7 (totally agree). The PTCI-Self measured the extent to which individuals had a negative view of him/herself and symptoms and thoughts of helplessness and alienation. The PTCI-World measured the degree to which individuals lack trust in others and believe the world to be unsafe. The PTCI-Blame scale measured the extent to which individuals attribute the occurrence of the event to something he/she did or did not do.

The three PTCI subscales and total score have demonstrated excellent internal consistency as follows: total score ( $\alpha=.97)$; Negative Cognitions About Self, $(\alpha=.97)$; Negative Cognitions About the World $(\alpha=.88)$; Self Blame $(\alpha=.86)$ as well as good testretest reliability ranging from .74-.89 (Foa, Ehlers, Clark, Tolin, \& Orsillo, 1999). In addition, the PTCI has demonstrated excellent convergent validity and discriminant validity (Foa, Ehlers, Clark, Tolin, \& Orsillo, 1999). When comparing traumatized individuals with and without PTSD, the ability for the PTCI to discriminate between 
groups was high for each scale (Cohen's $d=1.24-2.05$ ). Similarly, the scale's ability to differentiate between individuals with PTSD and non-traumatized individual yielded large effect sizes (Cohen's $d=0.90-1.90)$.

The PTCI total score was calculated by summing all items. Subscale scores are calculated as the mean item response for each subscale (Foa et al., 1999). In the current study, the PTCI subscales and total score demonstrated excellent internal consistency: Total Score ( $\alpha=.97)$; Negative Cognitions About Self, $(\alpha=.96)$; Negative Cognitions About the World ( $\alpha=.90)$; Self Blame (.79).

Health Functioning. Participants completed a measure of current mental and physical health functioning, The Medical Outcome Study Short Form (SF-36; McHorney, Ware, \& Raczek, 1993). The SF-36 is a self-report questionnaire that is a reliable and valid measure of physical and mental health-related functioning. It measures health on eight multi-item dimensions, covering functional status, wellbeing and overall evaluation of health (Brazier et al., 1992). For each dimension, items scores are coded, summed, and transformed on a scale from 0 (worst health) to 100 (best health). The SF36 is a generic measure, one that does not target a specific age group or disease, but instead, can be used with diverse populations. It was designed for use in surveys of general and specific populations, health policy evaluations, clinical practice and/or research.

The SF-36 has been widely used in clinical studies and has demonstrated adequate psychometric integrity (McHorney, Ware, \& Raczek, 1993; Ware \& Sherbourne, 1992). Factor analytic studies confirm that the eight scales assessing eight different health concepts make up two distinct factors: mental health and physical 
health, and that these factors account for $80-85 \%$ of the reliable variance in the eight scales in the U.S general population (Ware, Kosinski \& Keller, 1994). The Mental Component Summary score (MCS) is made up of three scales: Mental Health (MH), Role-Emotional (RE), and Social Functioning (SF) and Physical Component Summary score (PCS) is made up of three scales: Physical Functioning (PF), Role-Physical (RP), Bodily Pain (BP). The eight dimensions have a median reliability coefficient equal or greater than 0.80 , except for SF which had a median reliability across studies of 0.76 . For the PCS, relative validity coefficients range from .20 to .94 (median, .79) and from .93 to 1.45 (median, 1.02) for the MCS (Ware et al., 1995). As a result, the summary measures demonstrate adequate empiric validity (Ware et al., 1995). In addition, the SF36 demonstrated high test-retest reliability (correlation $=.60-.81$ ) and high levels of internal consistency (Cronbach's $a=0.73-0.96)$. In the current study, the Cronbach alpha coefficient was .71. Validation studies support the SF-36's convergent and discriminant validity when compared to similar measures (e.g., Nottingham questionnaire) (Braizer et al., 1992). For the current study, the MCS and PCS composite scores served as indicators of physical and mental health functioning. Scores on the composite scales range from 0 to 100 with lower scores indicating more impaired functioning.

Healthcare Utilization. Participants completed a measure of health care utilization (modified from Newman et al., 2000). The Health Care Utilization Questionnaire (HCUQ) was designed specifically for this study and based on a measure used by Newman and colleagues (1998). Participants were asked to self-report the number of health care visits (same categories as mention above) over the six months 
prior to the date of participation (i.e., September - February) using a five-point Likert scale. Each item on the Likert scale represents a range of visits ( $1=1-3$ visits; $2=4-6$ visits; $3=7-9$ visits; $4=10-12$ visits; $5=>12$ visits) (Newman, 1998). Participants were asked: "Since September (six months ago), have you seen a health professional about your mental or physical health?" If yes, participants were asked to indicate the type of visit and frequency on the five-point Likert scale. This measure has been found to have high test-retest reliability over a 2-week period (Newman, 1998).

PTSD-Symptomatology. Participants were asked to complete the Posttraumatic Diagnostic Scale (PDS), a measure of adult trauma and current PTSD symptomatology (Foa, Cashman, Jaycox, Perry, 1997). The PDS is a 49-item self-report measure that assesses severity of PTSD symptoms related to a single identified traumatic event. This is a unique scale in that it accounts for all of the DSM-IV criteria for PTSD (i.e., Criteria A-F) and inquires about the past month. In addition, while it measures symptom severity (Criteria B-D), it also assess the experience of a Criterion A traumatic event, duration of symptoms (Criterion E) and effects on daily functioning (Criterion F). As such, the PDS is comprised of four parts: 12-item checklist of traumatic events (Part 1), description of the most upsetting event (Part 2), questions specifically aimed at the 17 PTSD symptoms in relation to the traumatic event by rating the severity from 0 ("not at all or only one time") to 3 ("5 or more times a week/almost always) (Part 3). The final section (Part 4) assesses interference. For the current study, part 1 was used to determine the presence of adult trauma (traumatic events including maltreatment occurring since age 18). A summary score from Part 3 served as the indicator of the presence of PTSD symptomatology. Individuals were divided into two groups: 1) individuals who 
experienced a traumatic event with PTSD of at least moderate severity (score of 15 or above) and 2) individuals who experienced a traumatic event but did not have PTSD (PTSD-symptom severity score below 15) (Foa, Tolin, Ehlers, Clare, Orsillo, 1999). The PDS yields both dichotomous (diagnostic) and continuous scores (Orsillo 2001). Specifically, it yields a PTSD diagnosis according to the DSM-IV and a total severity score (0 to 51). Validation studies indicate high internal consistency for each symptom cluster $\mathrm{B}-\mathrm{D}(\mathrm{a}=.78-.84)$ and for the total scale $(\mathrm{a}=.92)$ (Foa, Cashman, Jaycox, Perry, 1997). Test-retest reliability coefficients over $2-3$ weeks were equally high for each cluster $(\mathrm{r}$ 's $=.77-.85)$ and for the total scale $(\mathrm{r}=.83)$. The PDS showed good agreement when compared to the Structured Clinical Interview for DSM-IV (SCID), the PDS and SCID yielded same diagnoses $82 \%$ of the time (kappa $=.65$ ). Scale sensitivity was found to be .89 and specificity .75 . In the current study, the Cronbach alpha coefficient was .91. 


\section{CHAPTER 4}

\section{FINDINGS}

\section{Preliminary Analyses}

A Missing Values Analysis (MVA) was conducted to determine patterns of missing values (Tabachnick \& Fidell, 2007). The PTCI scale had 6.6\% missing data and the HCUQ scale had nearly 50\% missing data; all other scales demonstrated less than 5\% missingness. Due to the significant amount of missing data on the HCUQ (i.e., greater than 5\%) and its nonrandom distribution, this measure was not used in the analyses (Tabachnick \& Fidell, 2007). For the PTCI, however, the distribution of missing data was determined to be unpredictable and missing completely at random $(\mathrm{MCAR}), \mathrm{X}^{2}(46)=52.63, p=.23$. Since missing values that are distributed randomly throughout the data matrix pose less significant problems, those cases with missing data were not included in the main analyses (N=28) (Tabacknick \& Fidell, 2007). All other questionnaires included in these analyses had less than 5\% missing data.

Traditional maximum likelihood methods of structural equation modeling (SEM) assume that continuous variables in the model are normally distributed (Kline, 2010). Preliminary analyses of univariate (e.g., means, standard deviations, skewness, and kurtosis) and multivariate normality indicated that the CTQ scores were positively skewed and highly kurtotic. For instance, $64.8 \%$ of the maltreated sample reported at least moderate levels of childhood maltreatment. Transformations were not made because it is reasonable to expect that these variables would be skewed in the population (i.e., most people do not experience moderate to severe instances of childhood 
maltreatment) (Tabachnick \& Fidell, 2007). To take nonnormality into account, the decision was made to use ROBUST statistical methods, provided by EQS Structural Equation Modeling software. ROBUST methods assess chi square statistics and standard errors by use of maximum likelihood estimation with the Satorra-Bentler scaled chi square and adjust the standard errors to the extent of the nonnormality (Tabachnick \& Fidell, 2007).

Mean, standard deviations and observed ranges for all variables are presented in Table 2. Based on the standards for categorization provided by Bernstein and Fink (1998), $44.7 \%$ of the original set of participants reported experiencing at least minimal levels of childhood maltreatment. See Table 3 for the percentage of participants endorsing each level of maltreatment for each type of maltreatment. All individuals included in the analyses endorsed at least one form of trauma meeting of at least minimal severity.

\section{Exploratory Analyses}

A series of independent samples $t$-tests were conducted on all dependent measures to test for gender differences. On most variables, gender differences were not found to be statistically significant. Females, however, were found to report significantly more emotional abuse on the CTQ than males $(M=50.86, S D=10.19$ versus $M=47.39, S D=8.96), t(283)=-2.57, p=.01$. Females also reported significantly poorer mental health functioning on the SF-36 than males ( $M=36.28, S D$ $=13.53$ vs. $M=43.26, S D=11.64), t(284)=3.92, p<.001$. Finally, females reported significantly more negative cognitions about the world than males $(M=4.03, S D=1.36$ vs. $M=3.58, S D=1.44), t(278)=-2.37, p<.05$. The magnitude of the differences in 
means between men and women ranged from relatively small to moderate, emotional abuse (Cohen's $d=0.36$ ), negative cognitions about the world (Cohen's $d=0.32$ ) and mental health functioning (Cohen's $d=0.55$ ). While these results suggest some potential gender differences, gender was not evaluated as a moderator due to small sample size of male participants $(\mathrm{N}=72)($ Kline, 2010).

A series of independent samples t-tests were conducted to evaluate whether individuals who endorsed current PTSD-symptomatology differed from those without current symptomatology on the identified variables. Of the 287 participants who endorsed childhood maltreatment, only 189 endorsed a more recent trauma on the PDS scale. Among these participants, 72 participants endorsed current symptoms of PTSD based on cut off scores provided by Foa and colleagues (see Foa et al., 1999), whereas 117 did not endorse symptomatology. On most variables, significant group differences were found. See Table 4 for t-test results and effect sizes. While the magnitude of effect sizes ranged from small to large based on guidelines provided by Cohen (Tabachnick \& Fidell, 2007), small sample sizes precluded measuring symptoms of PTSD as a moderator variable (Kline, 2010).

\section{Hypotheses $1-3$}

Bivariate Analyses. Regression analyses were conducted to evaluate the hypothesized model structure and determine the direct relations between the different forms of maltreatment and the dependent variables (i.e., posttraumatic cognitions and health outcomes). Childhood maltreatment explained $21.3 \%$ of the variance in posttraumatic cognitions, $F(5,259)=15.32, \mathrm{p}<.001$. The size and direction of the relationship suggest that childhood maltreatment is a significant predictor of more 
negative posttraumatic cognitions (Hypothesis 1). Specifically, emotional and sexual abuse were significant predictors of this outcome (See Table 5). Childhood maltreatment explained $13.4 \%$ of the variance in mental health outcomes, $F(5,275)=$ $9.638, \mathrm{p}<.001$ (See Table 6 ), and $8.7 \%$ of the variance in physical health outcomes, $F$ $(5,275)=6.342, \mathrm{p}<.001($ See Table 7$)$. The size and direction of the relationships indicate that childhood maltreatment is a significant predictor of poorer mental and physical health outcomes (Hypothesis 2). In particular, emotional, sexual and physical abuse contributed significantly to poorer mental and physical health outcomes. Tables 5-7 display the correlations between variables, unstandardized regression coefficients and standard errors. Based on these results, emotional and physical neglect were not supported as significant predictors of posttraumatic cognitions or mental and physical health outcomes.

The relationship between posttraumatic cognitions and mental and physical health outcomes was investigated using Pearson's correlation coefficient (Hypothesis 3). There was a significant negative correlation in the hypothesized direction between posttraumatic cognitions and mental health outcomes $(r=-.59, \mathrm{p}<0.01)$. There was also a significant, negative correlation in the hypothesized direction between posttraumatic cognitions and physical health outcomes $(r=-.19, \mathrm{p}<0.01)$. Taken together, emotional, physical, and sexual abuse were supported as significant predictors of more negative posttraumatic cognitions and poorer health outcomes, and more negative posttraumatic cognitions were associated with poorer health outcomes. Due to these findings, model modifications were made to remove emotional and physical neglect as indictors of the Childhood Maltreatment factor (see Figure 4). 


\section{Hypothesis 4}

Latent Variable Path Analyses for Childhood Maltreatment. Two

principal components analyses (PCA) were performed using SPSS (Version 20) on the two constructs in the hypothesized latent variable model (see Figure 1). Specifically, PCAs were used to determine if each of the subscales loaded onto the single hypothesized factor. The hypothesized model is presented in Figure 1 where circles represent latent variables, and rectangles represent measured variables. Absence of a line connecting variables implies no hypothesized direct effect. Emotional, sexual, and physical abuse and emotional and physical neglect subscales were hypothesized as indicators of the Childhood Maltreatment factor. PCA with oblique rotation was conducted to confirm the factor structure of the Childhood Maltreatment factor. Results supported the proposed factor, with each subscale loading onto the Childhood Maltreatment factor. Factor loadings ranged from 0.53 to 0.76 and accounted for $45.86 \%$ of the variance. Cognitions about the self, others and self-blame were hypothesized as indicators of the Posttraumatic Cognitions factor. All items loaded on to the Posttraumatic Cognitions factor. Factor loadings ranged from 0.83 to 0.91 and accounted for $75.29 \%$ of the variance.

To meet MacKinnon's (2008) criteria for establishing mediation, methods assessing indirect effects in a mediational model were utilized. MacKinnon's method is preferable to the traditional causal steps method outlined by Baron and Kenny (1986) because the traditional test has been demonstrated to be underpowered (Fritz \& MacKinnon, 2007). Structural equation model testing was conducted using the EQS 6.1 statistical software program (Bentler, 2003). 
Correlational analyses indicated that all forms of childhood maltreatment were significantly correlated with each other and with posttraumatic cognitions and health outcomes. To determine whether posttraumatic cognitions mediate the relationship between childhood maltreatment and health outcomes (i.e., mental [MCS] and physical [PCS]), latent variable path analyses were conducted. To test the relationship between childhood maltreatment and health outcomes and explain the variances and covariances, several nested models were tested. This method is designed to evaluate the way a set of factors and latent constructs relate and form a multivariate model (Schnoll, Harlow, Stolbach, \& Brandt, 1998). Three models (a full model, a mediational model, and a direct effects model) were analyzed for each outcome variable, using the maximum likelihood (ML) $\chi^{2}$ estimation method and fit indices (e.g., CFI, RMSEA) to evaluate the overall model. The full model (Figure 2) included all paths in order to evaluate whether childhood maltreatment directly affects health outcomes and whether posttraumatic cognitions indirectly mediate this relationship. The direct model (Figure 3) tested paths between childhood maltreatment and health outcomes to examine the direct effects of maltreatment independent of the proposed mediator.

Models were compared to one another in terms of their empirical fit with the data, using practical fit indices. Such indices included the comparative fit index (CFI; Bentler, 1990), the root mean square error of approximation (RMSEA; Steiger \& Lind, 1998), $R^{2}$ values for estimating effect size, and standardized regression path coefficients for each model (Harlow, 2007). The CFI is a normed fit index that adjusts for degrees of freedom. CFI greater than 0.90, and RMSEA of less than .10 are 
indicative of good fitting models (Bentler \& Wu, 1995). Insignificant chi-squares are ideal, however, due to the large sample size, it is expected that the chi- squares will be significant for the main analyses. If the macro fit indices for the model were deemed adequate, then the micro-fit indices were examined. These included the number of significant paths, their significance levels, and the strength of each relationship. For all analyses, a cutoff value for significance was set at $p=0.05$ and ROBUST methods were used when evaluating fit.

Model A: Childhood Maltreatment Full Model. Results indicated that the fully saturated model provided a marginally good fit to the data for the entire sample at the macro and micro level $\left(\chi^{2}(16, \mathrm{~N}=262)=50.58, \mathrm{p}<0.001 ; \mathrm{CFI}=0.93\right.$. RSMEA=0.09), as hypothesized. Analysis of the largest standardized residuals indicated that all relationships among observed variables were adequately explained by the model; no residual values exceeded $|0.20|$. Childhood abuse and posttraumatic cognitions had a large cumulative effect on mental health $\left(R^{2}=0.40\right)$, meaning that childhood abuse experiences and posttraumatic cognitions accounted for approximately $40 \%$ of the variance in mental health. Childhood abuse and Posttraumatic cognitions, however, had a small cumulative effect $\left(R^{2}=0.04\right)$ on physical health (i.e., CA and Posttraumatic cognitions accounted for only about $4 \%$ of the variance in physical health). Standardized parameter estimates are shown in Figure 2. The regression path between child abuse and Posttraumatic cognitions and path between Posttraumatic cognitions and mental health were significant at the $p<0.05$ level. The path between Posttraumatic cognitions and physical health was not significant. Importantly, the Wald test indicated that the following parameters should 
be dropped from the model to improve fit, 1) childhood abuse to physical health, 2) posttraumatic cognitions to physical health, and 3) childhood maltreatment to mental health. The LaGrange Multiplier test indicated that no parameters should be added to the model, as the degrees of freedom in the full model would not permit an additional parameter estimate.

Model B: Childhood Maltreatment Mediation Model. Results indicated that the meditational model provided a good fit to the data for the entire sample at the macro and micro level $\left(\chi^{2}(17, \mathrm{~N}=262)=37.98, \mathrm{p}<0.01 ; \mathrm{CFI}=.0 .96\right.$; RMSEA=0.07), as hypothesized. Analysis of the largest standardized residuals indicated that all relationships among observed variables were adequately explained by the model; no residual values exceeded $|0.20|$. Childhood abuse had a large effect on posttraumatic cognitions $\left(R^{2}=0.67\right)$, indicating that childhood abuse accounted for approximately $67 \%$ of the variance in posttraumatic cognitions. In addition, posttraumatic cognitions had a large effect on mental health $\left(R^{2}=0.40\right)$, meaning that posttraumatic cognitions accounted for approximately $40 \%$ of the variance in mental health. Posttraumatic cognitions, however, had a small effect $\left(R^{2}=0.04\right)$ on physical health (i.e., Posttraumatic cognitions accounted for only about $4 \%$ of the variance in physical health). Standardized parameter estimates are shown in Figure 4. All regression paths were significant at the $p<0.05$ level. Additionally, the Wald test indicated that no parameters should be dropped from the model to improve fit. The LaGrange Multiplier test, however, indicated that an error covariance between mental health and blame should be added. 
Model C: Childhood Maltreatment Direct Model. Results indicated that the direct effects model did not provide a good fit for the data at the macro and micro levels $\left(\chi^{2}(19, \mathrm{~N}=262)=197.46, \mathrm{p}<0.001 ; \mathrm{CFI}=.0 .62 ; \mathrm{RSMEA}=0.19\right)$. The RMSEA value, for instance, indicates that a significant portion of the variance in the dependent variables was left unaccounted for by this model. Analysis of the largest standardized residuals indicated values exceeding $|0.20|$, which indicates that this model did not adequately explain posttraumatic cognitions relationships with childhood maltreatment and mental and physical health outcomes. This was to be expected since the parameters relating to posttraumatic cognitions were held constant in the direct effects model. Standardized parameter estimates are shown in Figure 3. Because the direct model was not a good fit, estimates of individual parameters were unreliable and therefore not analyzed. The Lagrange Multiplier test suggested adding the following parameters, 1) posttraumatic cognitions to mental health and 2) childhood maltreatment to posttraumatic cognitions.

Overall, the mediational model, the model in which the relationship between childhood maltreatment and mental and physical health outcomes is indirect (i.e., mediated by posttraumatic cognitions), is the most appropriate model for the data based on parsimony and the criteria of empirical fit described above. The full model and the direct effects model each did not provide an adequate fit for the data. 


\section{CHAPTER 5}

\section{CONCLUSION}

The present study examined posttraumatic cognitions as mediators of the relationship between childhood maltreatment and adult mental/physical health outcomes. Importantly, this is one of the few studies that examined several types of maltreatment simultaneously in a sample of college students. Furthermore, it is the first to evaluate the meditating effect of posttraumatic cognitions on a broad set of mental and physical health outcomes not limited to PTSD.

In the current study, $44.7 \%$ of the initial sample $(\mathrm{N}=642)$ endorsed a history of childhood maltreatment of at least minimal severity. Among this maltreated group of participants, $62 \%$ percent reported a history of childhood emotional abuse, whereas $30 \%$ reported physical abuse and $25 \%$ reported sexual abuse. In addition, nearly $65 \%$ reported emotional neglect, while almost $39 \%$ reported physical neglect. Rates of maltreatment among male and female participants were relatively consistent with previous findings, with the exception of estimates of emotional and physical neglect, as these rates were slightly higher than some previous studies (e.g., Finkelhor, 1994; MacMillan et al., 1997; Bernstein \& Fink, 1998). Importantly, however, rates of emotional, physical and sexual abuse were consistent with several previous studies which utilized identical CTQ subscales and criteria to estimate the prevalence of childhood maltreatment among undergraduate students (Bernstein \& Fink, 1998; Turner \& Paivio, 2002; Wright et al., 2001; see Paivia \& Cramer, 2004 for details). 
Also notable was the severity of maltreatment reported in the current study. Participants were identified based on their responses on the Childhood Trauma Questionnaire. Cutoff scores of "low to moderate" for each type of maltreatment were used to identify participants who had experienced one or more forms of childhood abuse and/or neglect (Bernstein \& Fink, 1998) The lowest level cutoff scores were used in an effort to capture a high proportion of childhood maltreatment cases, including those of low severity (Paivio \& Cramer, 2004). Among participants endorsing a history of maltreatment, however, $64.8 \%$ reported moderate to severe forms of at least one type of maltreatment. More specifically, moderate to severe rates of each type of maltreatment reported were as follows: $27.5 \%$ emotional abuse, $16.4 \%$ reported physical abuse, $16.7 \%$ reported sexual abuse, $16.7 \%$ reported emotional neglect and $19.2 \%$ reported physical neglect. These findings are also consistent with previous research indicting high rates of multiple forms of abuse (Felitti et al., 1998; McGee, Wolfe, Yuen, Wilson, \& Carnochan, 1995).

As hypothesized, childhood maltreatment was supported as a predictor of poorer mental and physical health outcomes among young adults. This finding is consistent with previous research demonstrating the strong association between childhood maltreatment and mental (e.g., Arnow, 2004; Banyard, Williams, \& Siegel, 2001) and physical health difficulties (Walker at al., 1999; Felitti et al., 1998) in adulthood. More specifically, childhood abuse (i.e., sexual, physical and emotional abuse) accounted for $13.4 \%$ of the variance in mental health outcomes and $8.7 \%$ of the variance in physical health outcomes. 
Childhood maltreatment was also found to be directly related to more negative posttraumatic cognitions. Similar to the health outcome findings, childhood abuse (i.e., emotional and sexual) accounted for the variance in cognitions. That is, young adults who reported experiencing childhood emotional and/or sexual abuse were more likely to report more negative cognitions associated with their early traumatic experiences. This is consistent with previous studies indicating that adults with a history of sexual and emotional abuse tend to report more negative cognitions as compared to those without histories of maltreatment (e.g., Wenninger \& Ehlers, 1998).

Results supported the hypothesis that the relationship between childhood maltreatment and poorer health outcomes is mediated by posttraumatic cognitions. Previous research has identified negative cognitions that form after experiencing childhood maltreatment as important variables in the relationship between child maltreatment and the onset of PTSD and depression (Gibb et al., 2001; Kayson, Scher, Mastnak, Resick, 2005). The current findings extend this line of research to more broadly include mental health and physical health functioning and support the mediating effect of trauma-related cognitions in this relationship. Since cognitions were not found to explain all of the variance in health outcomes, the remaining variance may be attributed to the direct effects of maltreatment (e.g., lingering effects of earlier injuries or infections) or to the impact of other variables that were not examined in this study (e.g., depression, PTSD, and other mental health conditions, revicitimization in adulthood, other childhood adversities including neglect, poverty, and poor nutrition, as well as health-risk behaviors and medical conditions, such as 
alcohol and tobacco use and obesity) (Hager \& Runtz, 2012). It may also be due to measurement error and variability within the measures.

Importantly, mediational results indicate that experiences of maltreatment during childhood may lead to more negative cognitions about the self, and more generally, about the world. The current findings support the notion that early experiences of maltreatment may alter the way children think about themselves and their outlook on life. While some children go onto develop PTSD in response to maltreatment, for most, this is not the case. Trauma-related cognitions are likely incorporated into the child's schema, thereby affecting their long-term development not limited to the onset of PTSD. The current study suggests that it is these thoughts that may contribute to a child's future mental and physical health outcomes. The impact these trauma-related cognitions can have on child's development has the potential to be pervasive and affect the child's capacity to develop in a healthy manner.

The current study simultaneously examined the distinct forms of childhood maltreatment in an effort to control for the potential overlap among the different forms. Since the varying forms of maltreatment were not evaluated separately, the unique effects of emotional and physical neglect may have diminished when other forms of abuse were present, explaining the reason why abuse (e.g., sexual, emotional, and physical) emerged as the stronger predictor (Kayson, Scher, Mastnak, Resick, 2005). That being said, while the current study did not support physical and emotional neglect as strong predictors of health outcomes, it is possible they still contribute to the overall effect. Model fit for child abuse compared to models including neglect 
subscales were relatively similar. While it may be that the etiology of abuse is different than that of neglect, the relative stability in the two models suggests that neglect likely contributes similarly to overall outcomes. These findings point to the importance of studying multiple types of maltreatment simultaneously as it is not only difficult to parse out each form of maltreatment's effect, but also difficult to make sense of the interactions among the different forms leading to varying outcomes in adulthood (e.g., Edwards, Holden, Felitti, \& Anda, 2003; Kayson, Scher, Mastnak, Resick, 2005).

The limited support for posttraumatic cognitions as a mediator between childhood maltreatment and physical health outcomes may be a result of several factors. First, college students are inherently a healthier population. In the current sample, participants rated their physical health more positively than their mental health. College students also tend to have higher socioeconomic status than the larger population, and thus, overall physical health is likely to be better. Age may also be a contributing factor (mean age $=19$ ), as the types physical health-related issues assessed are less likely to emerge at such a young age. As such, it may be that physical health was less of a problem among this sample obscuring findings for physical health outcomes. Health risk behaviors (e.g., alcohol/drug use) may have also been more appropriate to assess among this population in an effort to target those behaviors that can lead to health problems later in life. It may also be that the types of cognitions assessed do not have as strong of a relationship with physical health and they do with mental health. It is possible that cognitions that form as a result of experiencing trauma may impact mental health functioning more strongly than physical health 
functioning. However, this seems less likely, as thoughts associated with self-esteem and competence have been linked to poorer health (e.g., Benyamini, Leventhal, \& Leventhal, 2004; L `'kikan- gas, Kinnunen, \& Feldt, 2004)

Furthermore, some gender differences were found. Women reported significantly more emotional abuse, poorer mental health functioning and more negative cognitions about the world as compared to men. However, the magnitude of differences was relatively small, which is possibly due to the small sample of men $(\mathrm{N}=72)$ versus women $(\mathrm{N}=215)$. As a result of the limited number of male participants, gender was not included as a moderator variable. The significant gender differences that were found, however, are consistent with previous research suggesting women's tendency to report more emotional abuse (Miller et al., 2011) and more negative cognitions than men (e.g., Ehlers \& Clarke, 2003). Differences in mental health related issues may be in part due to women's tendency to report more psychological issues than men (Keyes et al., 2011). Taken together, it is possible that the above findings are best attributed to undergraduate men being less apt to participate in a study of this kind due to the nature of the questions (e.g., related to "previous childhood experiences"). Despite efforts to engage both men and women participants by reaching out to various majors on campus (e.g., Biology, Math, History) women were more likely to participate. Future studies should consider the efforts put forth in this study to reach both men and women, and include more targeted outreach approaches to increase the number of male participants.

Finally, this study examined the relationship between childhood maltreatment and health outcomes in a young adult, undergraduate student sample. It is believed that 
the consequences of childhood maltreatment would be particularly salient among young adults, as college marks a transition in the developmental process from childhood to adulthood. With this in mind, young adults who have experienced maltreatment as a child likely developed some degree of maladaptive cognitions in relation to the traumatic experience. The inherent stress that comes along with any major life transition (e.g., high school to college) may serve to exacerbate the effects of such negative cognitions and, thus, begin the development of mental and/or physical health related issues. Or, it may be that simply the age at which individuals typically enter college (18-20 years old) is the prime developmental period for the onset of such difficulties. More simply put, by examining a group of college students, this study was able to evaluate whether or not poorer mental and physical health outcomes were already emerging, at a relatively young age, among this group of maltreated individuals. Further, while the current study did not control for extraneous variables (e.g., repeat victimization as an adult), sampling such a young group of individuals reduces the likelihood that these variables have had an opportunity to impact participants' functioning. Thus, support for the mediating effects of posttraumatic cognitions among this group of college students suggests that as early as 18 years old, individuals with a history of childhood maltreatment are already experiencing negative health-related outcomes.

\section{Limitations of the Present Study}

Several methodological limitations of this study should be noted. First, the cross-sectional, correlational design of this study precludes conclusions about causality in the relationships between the variables. While most research in childhood 
maltreatment relies on retrospective reports, it is important to note the drawbacks of this method. A temporal sequence was artificially created in this study by asking participants to report traumatic experiences "prior to age 18 " in addition to cognitions related to these experiences. However, while structural equation modeling (SEM) methods (compared to alternative methods) have the capability of inferring causality, definitive statements can only be made with longitudinal data (Lang, et al., 2008). Since all variables in this study were assessed at a single time point, their potential roles as predictors, concomitants, or consequences cannot be determined with certainty. Therefore, neither casualty nor directionality can be assumed. Thus, it is impossible to determine whether negative trauma-related cognitions formed as a result of childhood maltreatment, resulted from, or caused more negative health outcomes. Nonetheless, the direction and ordering of the variables tested in this study were guided by robust theory and previous research (e.g., Gibb et al., 2001; Hagar \& Runtz, 2012; Kaysen, Scher, Mastnak \& Resick, 2005).

Second, the present study assessed childhood maltreatment retrospectively and relied on participants' memories for information about childhood experiences. Such recollections may be subject to recall bias. Despite this limitation, research largely supports the accuracy of retrospective self-reports of childhood maltreatment (e.g., Brewin, Andrews, and Gotlib, 1993). Similar to the drawbacks of cross-sectional research (discussed above), retrospective self-report studies constitute the core of the literature on the long-term effects of childhood maltreatment. Longitudinal studies would allow for more accurate assessment of early childhood experiences and traumarelated factors. 
An additional limitation is that the present study relied exclusively on selfreport measures. Therefore, the associations among variables could partly be accounted for by shared method variance, a threat to construct validity. Self-report tools are also vulnerable to effects of mood and social desirability (Hagar \& Runtz, 2012). This may help to explain the limited data collected on health care utilization. For example, it may have been that college students had difficulty remembering their last visit to the doctor (despite limiting the question to a 6-month period). It is also possible that participants had not been to the doctor in the past six-months, inherently limiting the number of participants who completed this questionnaire.

Generalizability is limited based on the homogenous nature of the current sample. Not only did the study focus exclusively on college students, the sample was limited in ethnic/racial and socioeconomic diversity. As such, it was composed of predominantly white, upper-middle class, undergraduate students which precluded testing for a number of potential demographic differences. Importantly, study findings may not generalize to other groups. It is possible that similar models may not find the same degree of fit with a more diverse population. Further, due to the tendency for college students to be a healthier subset of the overall population, it is likely that the current sample's mental and physical health functioning was higher than what would be found in a community sample. As such, future studies should aim to replicate findings in a more diverse group of young adults. In addition, studies should consider the impact of sociocultural factors on childhood maltreatment, posttraumatic cognitions, and long-term health outcomes. It would be particularly important to determine the role cultural and ethnic factors play in this relationship. 


\section{Implications of Study Findings}

The results of the current study have significant implications for informing future studies and, perhaps most importantly, for improving prevention and treatment efforts. To begin, this study confirms the widespread occurrence of childhood maltreatment in a select sample of students who agreed to participate in a study about maltreatment and lends support for it as a major public health issue. In addition, study findings contribute to a better understanding of the impact of trauma-related cognitions on longer-term mental health outcomes. To date, most of the research has focused on the effect of posttraumatic cognitions on the development of PTSD and acute stress disorder. Thus, the present findings help to broaden the conceptualization of childhood maltreatment by assessing multiple forms of maltreatment (as opposed to just one) and contribute to a better understanding of the prognosis of early traumatic experiences.

Moreover, results point to the importance of prevention-based efforts as a way to reduce risk for long-term health problems. Specifically, while cognitive-behavioral therapy interventions have been established as the first line of treatment for many mental health-related issues (e.g., PTSD, anxiety, depression), similar interventions may be useful in preventing the onset of long-term mental and physical health difficulties among children who experience maltreatment. That is if maladaptive cognitions do in fact antedate the onset of mental and physical health concerns among victims of early maltreatment, then intervention programs aimed at cognitive restructuring and skill building (e.g., affect regulation, meaning-making) may help to mitigate the development of posttraumatic cognitions and subsequent health problems. 
At present, most children receive interventions if: 1) the maltreatment is reported and interventions are mandated or, 2) if the child is experiencing distress as it relates to the trauma. While not all children go onto develop this type of distress, this line of research suggests that interventions aimed more specifically at trauma-related cognitions may help to reduce the likelihood of later mental health problems.

At minimum, it would seem to follow that more improved assessment measures for children who have experienced maltreatment are needed to not only target distress (e.g., depressive/anxious symptoms related to the trauma), but also, to target potential posttraumatic cognitions. Therefore, whether or not a child experiences distress early on, the child could at least receive interventions aimed at correcting dysfunctional cognitions, subsequently reducing their risk for later mental health issues. Such preventative efforts could also be aimed at increasing a child's cognitive flexibility, as more rigid concepts about the self and the world may place children at risk for developing subsequent psychopathology by making it difficult to incorporate the experience of a traumatic event into existing schemas (see Foa \& Rothbaum's emotional processing theory, 1998).

There is also the possibility that unexamined variables account for some of the affects attributed to maltreatment, posttraumatic cognitions and health outcomes in the present model. Children who experience maltreatment also frequently experience other risk factors (e.g., low socioeconomic status, household dysfunction) which can further complicate a child's development (Appleyard, Egland, van Dulman, \& Sroufe, 2005; Appleyard, Yang \& Runyan, 2010). As a result, such factors may help to explain the development of posttraumatic cognitions. It is possible that these factors 
increase the risk of posttraumatic cognitions, as they may contribute to the formation of maladaptive schemas at an early age.

\section{Future Directions}

Based on study findings and limitations, future research should seek to clarify a number of questions raised by the current study. Due to the relatively homogenous sample, future studies should aim to evaluate this model in a more diverse group of young adults in an effort to enhance the generalizability of findings. In addition, the inclusion of both subjective (e.g., self-report, family/friends reports) and objective methods of data collection (e.g., records review), as well as, a lifetime clinical interview should be utilized to enhance the reliability of self-report measures.

Moreover, in an effort to understand the potentially devastating effects of childhood maltreatment, studies that are longitudinal in design are needed. Future prospective longitudinal research will allow for a more comprehensive understanding of the etiology of mental/physical health outcomes among survivors of childhood maltreatment and clarify the directionality of these relationships. Continued examination of these issues with multiple measures over time will help to clarify the developmental processes involved in the long-term effects of maltreatment. Finally, this study only begins to touch on the important mechanisms involved in the relationship between childhood maltreatment and health problems later in life. Therefore, it is essential that future research continue to identify the mediating and moderating variables (e.g., stress level, family/social support, family dysfunction; SES) associated with this relationship in an effort to more effectively inform treatment and prevention efforts. 
In summary, the present study supports the relationship between childhood maltreatment and health outcomes as mediated by posttraumatic cognitions among young adults. Thus, the manner in which young adults view themselves and the world around them as related to their early traumatic experiences appears to play a significant role in the later development of mental and physical health outcomes. These findings support the timely implementation of trauma-focused cognitive behavioral interventions. Such interventions, aimed at working with survivors of childhood maltreatment to address cognitive distortions and related symptomatology could possibly offset the development of posttraumatic cognitions, and subsequently, the development of mental and physical health problems later in life. Further research is need to continue to elucidate mechanisms involved in the link between childhood maltreatment and poorer health outcomes in order to more effectively facilitate optimal development for children. 
Table 1

\section{TABLES}

Participant Characteristics

\begin{tabular}{|c|c|c|c|}
\hline & $\begin{array}{l}\text { Men } \\
N(\%)\end{array}$ & $\begin{array}{l}\text { Women } \\
\mathrm{N}(\%)\end{array}$ & $\begin{array}{l}\text { Total } \\
\text { N (\%) }\end{array}$ \\
\hline Age Range & $18-26$ & $18-45$ & $18-45$ \\
\hline Mean Age & 19.81 & 19.93 & 19.90 \\
\hline \multicolumn{4}{|l|}{ Race/Ethnicity $^{\mathrm{a}}$} \\
\hline White & $59(81.9)$ & $177(82.3)$ & $236(82.2)$ \\
\hline Black/African American & $5(6.9)$ & $9(4.2)$ & $14(4.9)$ \\
\hline Asian & $4(5.6)$ & $9(4.2)$ & $13(4.5)$ \\
\hline Hispanic/Latino & $5(6.9)$ & $29(13.5)$ & $34(11.8)$ \\
\hline \multicolumn{4}{|l|}{ Education Level $^{\mathrm{b}}$} \\
\hline Freshman & $25(34.7)$ & $81(37.7)$ & $106(36.9)$ \\
\hline Sophomore & $30(41.7)$ & $62(28.8)$ & $92(32.1)$ \\
\hline Junior & $9(12.5)$ & $44(20.5)$ & $53(18.5)$ \\
\hline Senior & $7(9.7)$ & $24(11.2)$ & $31(10.8)$ \\
\hline \multicolumn{4}{|l|}{ Martial Status ${ }^{c}$} \\
\hline Single & $71(98.6)$ & $204(94.9)$ & $275(95.8)$ \\
\hline Married & 0 & $4(1.9)$ & $4(1.4)$ \\
\hline Divorced/Separated & 0 & $2(0.9)$ & $2(0.7)$ \\
\hline Widowed & 0 & $2(0.9)$ & $2(0.7)$ \\
\hline \multicolumn{4}{|l|}{ Parents' Education Level ${ }^{\mathrm{d}}$ (dad) } \\
\hline$<$ High School & $4(5.6)$ & $16(7.4)$ & $20(7)$ \\
\hline High School Graduate & $13(18.1)$ & $51(23.7)$ & $64(22.3)$ \\
\hline Some College & $114(19.4)$ & $38(17.7)$ & $52(18.1)$ \\
\hline 2-Year Degree & $5(6.9)$ & $25(11.6)$ & $30(10.5)$ \\
\hline 4-Year Degree & $22(30.6)$ & $47(21.9)$ & $69(24)$ \\
\hline Master's Level & $9(12.5)$ & $30(13.9)$ & $7(9.4)$ \\
\hline $\mathrm{MD} / \mathrm{PhD}$ & $5(7.0)$ & $6(2.8)$ & $11(3.8)$ \\
\hline \multicolumn{4}{|l|}{ Annual Family Income $e^{\mathrm{e}}$} \\
\hline$\$ 0-\$ 39,000$ & $13(18.2)$ & $50(23.3)$ & $63(21.9)$ \\
\hline$\$ 40,000-\$ 69,000$ & $15(20.7)$ & $51(23.7)$ & $66(23)$ \\
\hline$\$ 70,000-\$ 99,000$ & $12(16.7)$ & $48(22.3)$ & $50(21)$ \\
\hline$>\$ 100,000$ & $25(34.8)$ & $51(23.7)$ & $76(26.5)$ \\
\hline Family History of Medical Problems (Yes) & $34(47.2)$ & $119(55.3)$ & $153(53.3)$ \\
\hline $\begin{array}{l}\text { Family History of Mental Health Problems } \\
(\text { Yes })^{\mathrm{f}}\end{array}$ & $15(20.8)$ & $84(39.1)$ & $99(34.5)$ \\
\hline Currently Living On Campus (Yes) & $38(52.8)$ & $117(54.4)$ & $155(54)$ \\
\hline Currently Have Health Insurance (Yes) & $68(94.4)$ & $194(90.2)$ & $262(91.3)$ \\
\hline
\end{tabular}


Table 2

Means, Standard Deviations, and Observed Ranges for Scores on the CTQ, PTCI, and $S F-36$

\begin{tabular}{lcccc}
\hline Variable & Range & $\begin{array}{c}\text { Female } \\
(\mathrm{N}=215)\end{array}$ & $\begin{array}{c}\text { Male } \\
(\mathrm{N}=72)\end{array}$ & $\begin{array}{c}\text { Total } \\
(\mathrm{N}=287)\end{array}$ \\
\cline { 2 - 4 } CTQ -SA & $5-25$ & $\mathrm{M}(\mathrm{SD})$ & $\mathrm{M}(\mathrm{SD})$ & $\mathrm{M}(\mathrm{SD})$ \\
\cline { 2 - 4 } CTQ -EA & $5-25$ & $10.73(4.42)$ & $9.23(3.88)$ & $10.36(4.34)$ \\
CTQ-PA & $5-24$ & $7.12(3.31)$ & $7.46(3.62)$ & $7.20(3.39)$ \\
CTQ-EN & $5-25$ & $10.53(3.98)$ & $11.38(3.48)$ & $10.74(3.88)$ \\
CTQ-PN & $5-19$ & $7.24(2.68)$ & $7.82(2.63)$ & $7.38(2.67)$ \\
PTCI-Total & $36-242$ & $103.96(40.46)$ & $94.27(38.92)$ & $101.57(40.23)$ \\
PTCI-World & $1-7$ & $4.03(1.35)$ & $3.58(1.44)$ & $3.92(1.39)$ \\
PTCI-Self & $1-6.62$ & $2.52(1.18)$ & $2.30(1.18)$ & $2.47(1.18)$ \\
PTCI-Blame & $1-6.81$ & $2.76(1.28)$ & $2.80(1.21)$ & $2.77(1.26)$ \\
SF-36-MCS & $1.20-71.77$ & $36.28(13.53)$ & $43.26(11.63)$ & $38.04(13.41)$ \\
SF-36-PCS & $29.65-73.03$ & $54.60(7.84)$ & $54.07(7.77)$ & $54.46(7.81)$ \\
\hline
\end{tabular}

Note. $\mathrm{CTQ}=$ Child Trauma Questionnaire; $\mathrm{SA}=$ Sexual Abuse $; \mathrm{EA}=$ Emotional Abuse; $\mathrm{PA}=$ Physical Abuse; EN = Emotional Neglect; PN = Physical Neglect; PTCI = Posttraumatic Cognitions Inventory; SF36-MCS $=$ The Medical Outcome Study Short Form Mental Health Composite Score; SF-36-PCS = The Medical Outcome Study Short Form Physical Health Composite Score. For the CTQ and PTCI scales, higher scores are indicative of more extreme responding in the direction of the construct assessed. For the SF-36, higher scores are indicative of improved functioning. 
Table 3

Rates of Different Forms of Maltreatment Endorsed Among Participants

\begin{tabular}{|c|c|c|c|c|}
\hline & $\begin{array}{l}\text { None } \\
\text { N (\%) }\end{array}$ & $\begin{array}{l}\text { Low to } \\
\text { Moderate } \\
\mathrm{N}(\%)\end{array}$ & $\begin{array}{c}\text { Moderate to } \\
\text { Severe } \\
\text { N (\%) }\end{array}$ & $\begin{array}{c}\text { Severe to } \\
\text { Extreme } \\
\mathrm{N}(\%)\end{array}$ \\
\hline Emotional Abuse $^{\mathrm{a}}$ & $107(37.3)$ & $99(34.5)$ & $38(13.2)$ & $41(14.3)$ \\
\hline Males & $36(50.0)$ & $19(26.4)$ & $9(12.5)$ & $7(9.7)$ \\
\hline Females & $71(33.0)$ & $80(37.2)$ & $29(13.5)$ & $34(15.8)$ \\
\hline Physical Abuse ${ }^{b}$ & $200(69.7)$ & $38(13.2)$ & $22(7.7)$ & $25(8.7)$ \\
\hline Males & $45(62.5)$ & $14(19.4)$ & $5(6.9)$ & $7(9.7)$ \\
\hline Females & $115(72.1)$ & $24(11.2)$ & $17(7.9)$ & $18(8.4)$ \\
\hline Sexual Abuse & 215 (74.9) & $24(8.4)$ & $17(5.9)$ & $31(10.8)$ \\
\hline Males & $56(77.8)$ & $6(8.3)$ & $2(2.8)$ & $8(11.1)$ \\
\hline Females & $159(74.0)$ & $18(8.4)$ & $15(7.0)$ & $23(10.7)$ \\
\hline Emotional Neglect ${ }^{\mathrm{c}}$ & $101(35.2)$ & $134(46.7)$ & $33(11.5)$ & $15(5.2)$ \\
\hline Males & $17(23.6)$ & $39(54.2)$ & $9(12.5)$ & $4(5.6)$ \\
\hline Females & $84(39.1)$ & $95(44.2)$ & $24(11.2)$ & $11(5.1)$ \\
\hline Physical Neglect $^{\mathrm{d}}$ & $176(61.3)$ & $54(18.8)$ & $39(13.6)$ & $16(5.6)$ \\
\hline Males & $37(51.4)$ & $16(22.2)$ & $14(19.4)$ & $9(12.5)$ \\
\hline Females & $139(64.7)$ & $38(17.7)$ & $25(11.6)$ & $12(5.6)$ \\
\hline Total $^{\mathrm{e}}$ & $0(0)$ & $242(84.3)$ & $106(36.9)$ & $80(27.9)$ \\
\hline Males & $0(0)$ & $62(86.1)$ & $26(36.1)$ & $19(26.4)$ \\
\hline Females & $0(0)$ & $180(83.7)$ & $80(37.2)$ & $61(28.4)$ \\
\hline
\end{tabular}

Note. ${ }^{a} \mathrm{~N}=2(0.7)$ were missing. ${ }^{b} \mathrm{~N}=2$ (0.7) were missing. ${ }^{c} \mathrm{~N}=4$ (1.4) were missing. ${ }^{\mathrm{d}} \mathrm{N}=2(0.7)$ were missing. ${ }^{\mathrm{e}}$ Groups are not mutually exclusive. 
Table 4

Comparison of Participants with Current PTSD-symptomatology and Participants Without PTSD-Symptomatology on the CTQ, PTCI, and SF-36

\begin{tabular}{lllll}
\hline \multicolumn{1}{c}{ Variable } & \multicolumn{1}{c}{$\begin{array}{c}\text { With PTSD } \\
(\mathrm{N}=72)\end{array}$} & $\begin{array}{c}\text { Without PTSD } \\
(\mathrm{N}=215)\end{array}$ & \multicolumn{1}{c}{$t(\mathrm{df})$} & Cohen's $d$ \\
\cline { 1 - 3 } CTQ-C & \multicolumn{1}{c}{$M(\mathrm{SD})$} & \multicolumn{1}{c}{$M(\mathrm{SD})$} & \\
\cline { 2 - 4 } CTQ-SA & $265.98(42.61)$ & $242.01(24.50)$ & $-4.64(182)^{* * *}$ & 0.66 \\
CTQ-EA & $53.46(14.70)$ & $48.49(6.33)$ & $-3.21(187)^{* *}$ & 0.44 \\
CTQ-PA & $55.22(10.97)$ & $48.02(9.26)$ & $-4.80(185)^{* * *}$ & 0.71 \\
CTQ-EN & $52.07(10.41)$ & $48.43(9.73)$ & $-2.43(186)^{*}$ & 0.46 \\
CTQ-PN & $51.32(11.60)$ & $49.23(8.91)$ & $-1.38(186)$ & 0.35 \\
PTCI-Total & $127.32(41.70)$ & $91.04(32.99)$ & $-6.46(178)^{* * *}$ & 0.96 \\
PTCI-World & $4.67(1.32)$ & $3.76(1.27)$ & $-4.62(183)^{* * *}$ & 0.70 \\
PTCI-Self & $3.23(1.21)$ & $2.11(.99)$ & $-6.82(180)^{* * *}$ & 1.01 \\
PTCI-Blame & $3.27(1.34)$ & $2.49(1.11)$ & $-4.31(186)^{* * *}$ & 0.63 \\
SF-36-MCS & $27.68(12.37)$ & $41.34(12.05)$ & $7.48(186)^{* * *}$ & 1.37 \\
SF-36-PCS & $52.76(9.75)$ & $55.54(7.08)$ & $2.27(186)^{*}$ & 0.33
\end{tabular}

Note. $\mathrm{CTQ}=$ Child Trauma Questionnaire; $\mathrm{C}=$ Composite score; $\mathrm{SA}=$ Sexual Abuse; $\mathrm{EA}=$ Emotional Abuse; $\mathrm{PA}=$ Physical Abuse; EN = Emotional Neglect; $\mathrm{PN}=$ Physical Neglect; $\mathrm{PTCI}=$ Posttraumatic Cognitions Inventory; SF-36-MCS = The Medical Outcome Study Short Form Mental Health Composite Score; SF-36-PCS = The Medical Outcome Study Short Form Physical Health Composite Score. $* \mathrm{p}<.05 . * * \mathrm{p}<.01 . * * * \mathrm{p}<.001$. 
Table 5

Standard Multiple Regression of Different Types of Childhood Maltreatment Predicting Posttraumatic Cognitions

\begin{tabular}{|c|c|c|c|}
\hline Predictor & $\mathrm{PTCI}^{\mathrm{a}}$ & $\mathrm{B}$ & $\mathrm{SE}$ \\
\hline Emotional Abuse & $.39 * * *$ & $1.29 * * *$ & 0.26 \\
\hline Sexual Abuse & $.34 * * *$ & $1.11 * * *$ & 0.24 \\
\hline Physical Abuse & $.13 *$ & -0.40 & 0.25 \\
\hline Emotional Neglect & $.27 * * *$ & 0.35 & 0.27 \\
\hline Physical Neglect & $.18 * *$ & -0.01 & 0.26 \\
\hline $\mathrm{R}^{2}$ & \multicolumn{3}{|l|}{0.23} \\
\hline \multicolumn{4}{|c|}{ 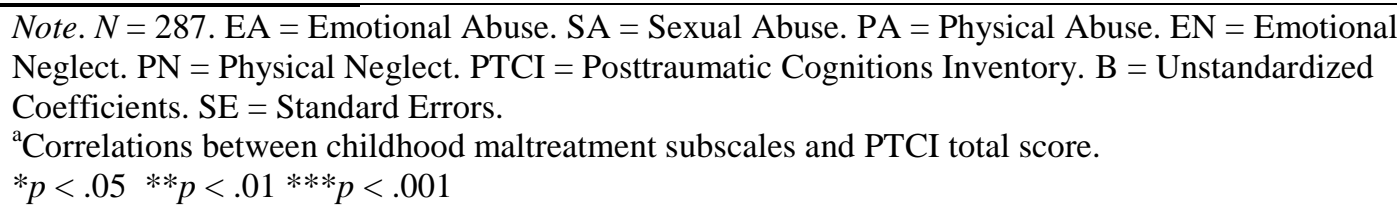 } \\
\hline
\end{tabular}


Table 6

Standard Multiple Regression of Different Types of Childhood Maltreatment Predicting Mental Health Outcomes

\begin{tabular}{|c|c|c|c|}
\hline Predictor & $\mathrm{MCS}^{\mathrm{a}}$ & B & $\mathrm{SE}$ \\
\hline Emotional Abuse & $-.34 * * *$ & $-0.51 * * *$ & 0.93 \\
\hline Sexual Abuse & $-.19 * * *$ & $-0.19 *$ & 0.08 \\
\hline Physical Abuse & -.05 & $0.19 *$ & 0.09 \\
\hline Emotional Neglect & $-.16^{* *}$ & 0.01 & 0.09 \\
\hline Physical Neglect & -.08 & 0.03 & 0.09 \\
\hline $\mathrm{R}^{2}$ & 0.15 & & \\
\hline \multicolumn{4}{|c|}{ 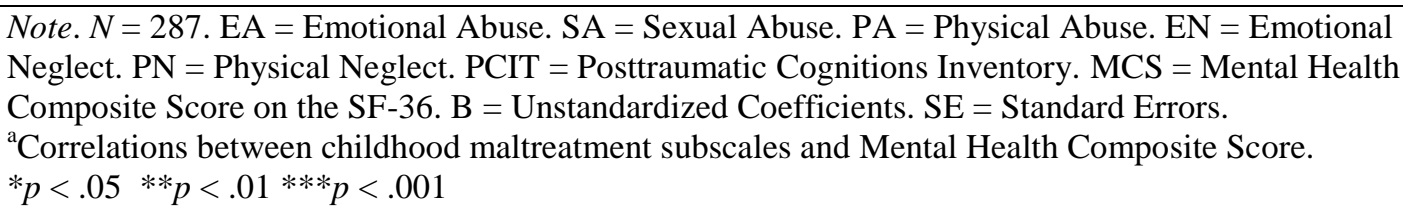 } \\
\hline
\end{tabular}


Table 7

Standard Multiple Regression of Different Types of Childhood Maltreatment Predicting Physical Health Outcomes

\begin{tabular}{llcc}
\hline Predictor & $\mathrm{PCS}^{\mathrm{a}}$ & $\mathrm{B}$ & $\mathrm{SE}$ \\
\hline Emotional Abuse & -.05 & $0.12^{*}$ & 0.06 \\
Sexual Abuse & $-.22 * * *$ & $-0.13^{*}$ & 0.05 \\
Physical Abuse & $-.23 * * *$ & $-0.16^{*}$ & 0.05 \\
Emotional Neglect & $-.14^{* *}$ & -0.08 & -0.06 \\
Physical Neglect & $-.19 * * *$ & -0.06 & 0.05 \\
$\mathrm{R}^{2}$ & 0.10 & & \\
\hline
\end{tabular}

Note. $N=287 . \mathrm{EA}=$ Emotional Abuse. $\mathrm{SA}=$ Sexual Abuse. $\mathrm{PA}=$ Physical Abuse. $\mathrm{EN}=$ Emotional Neglect. PN $=$ Physical Neglect. PCIT $=$ Posttraumatic Cognitions Inventory. PCS $=$ Physical Health Composite Score on the SF-36. B = Unstandardized Coefficients. SE = Standard Errors.

${ }^{\mathrm{a}}$ Correlations between childhood maltreatment subscales and Physical Health Composite Scores. $* p<.05 * * p<.01 * * * p<.001$ 


\section{FIGURES}

Figure 1. Proposed Mediational Model

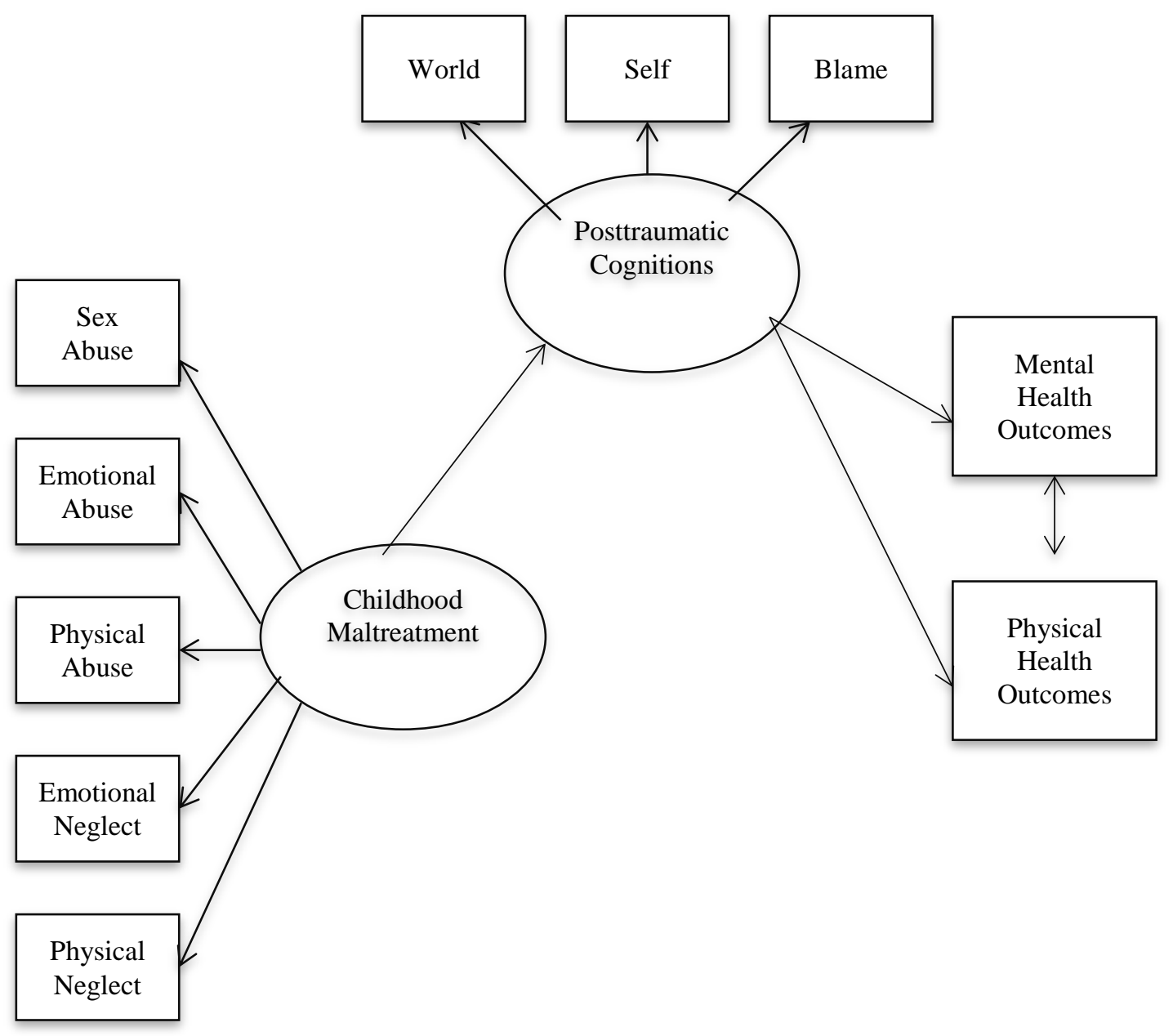


Figure 2. Full Model

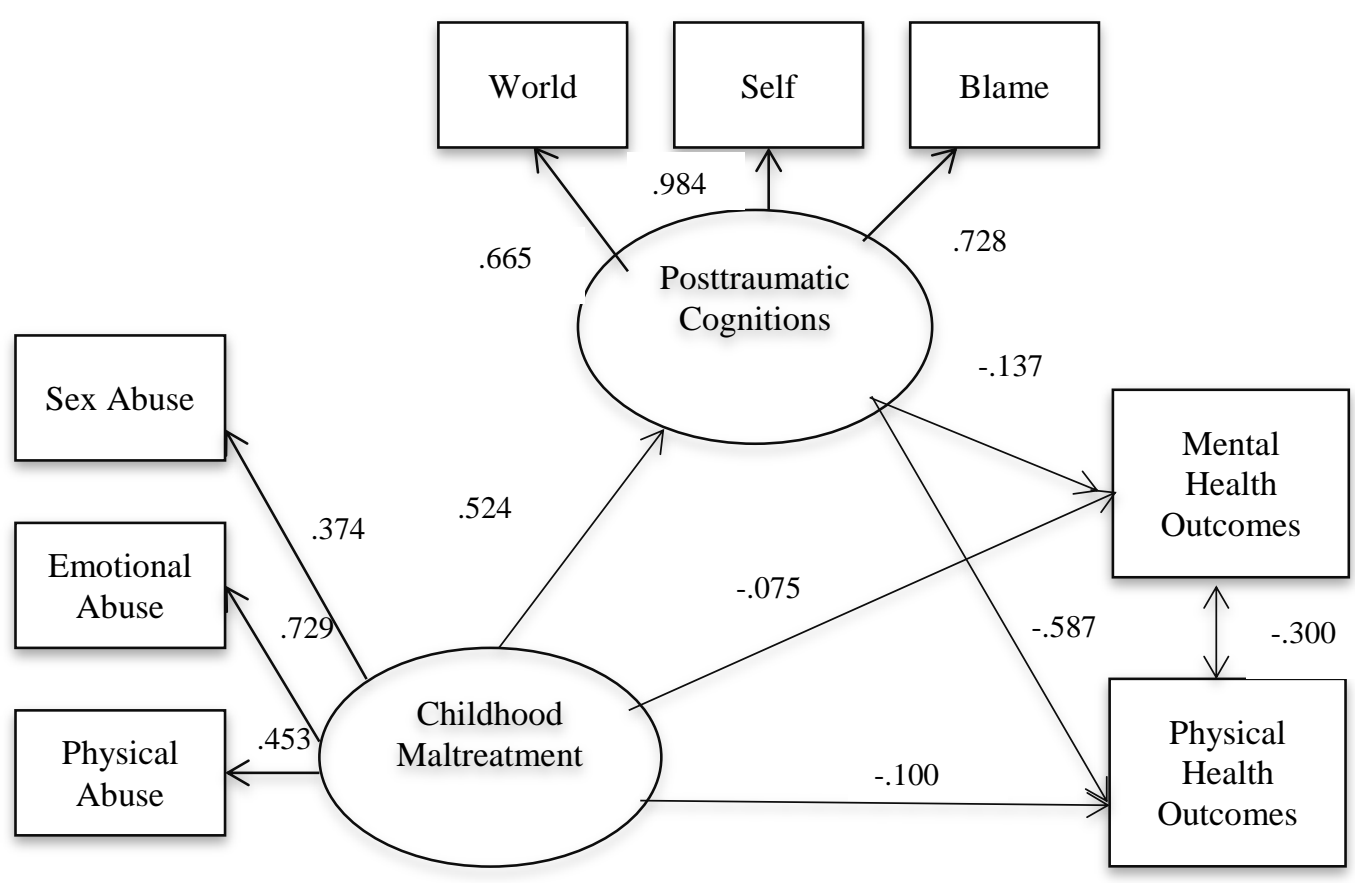


Figure 3. Direct Model

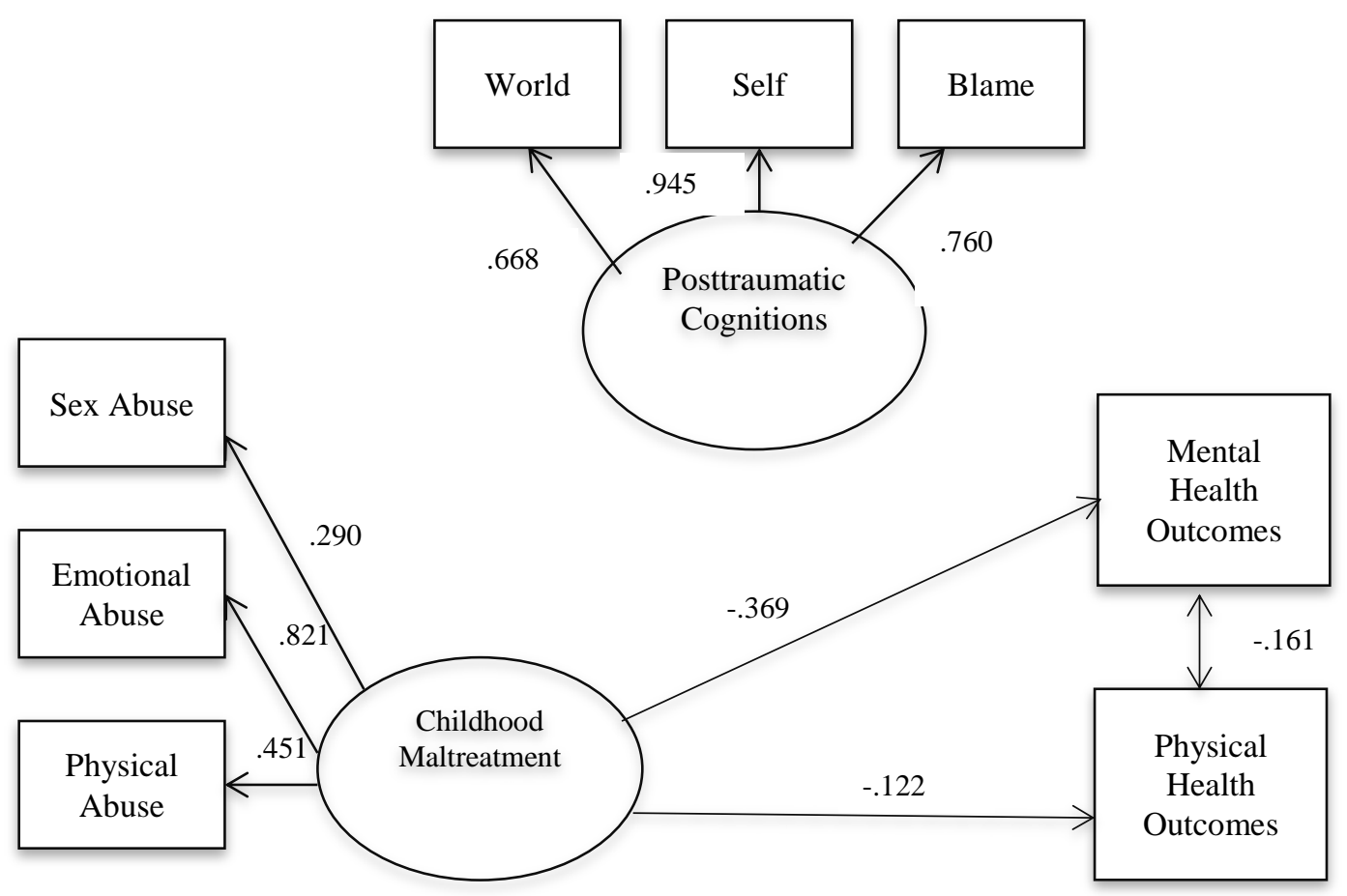


Figure 4. Modified Mediational Model and Standardized Solution

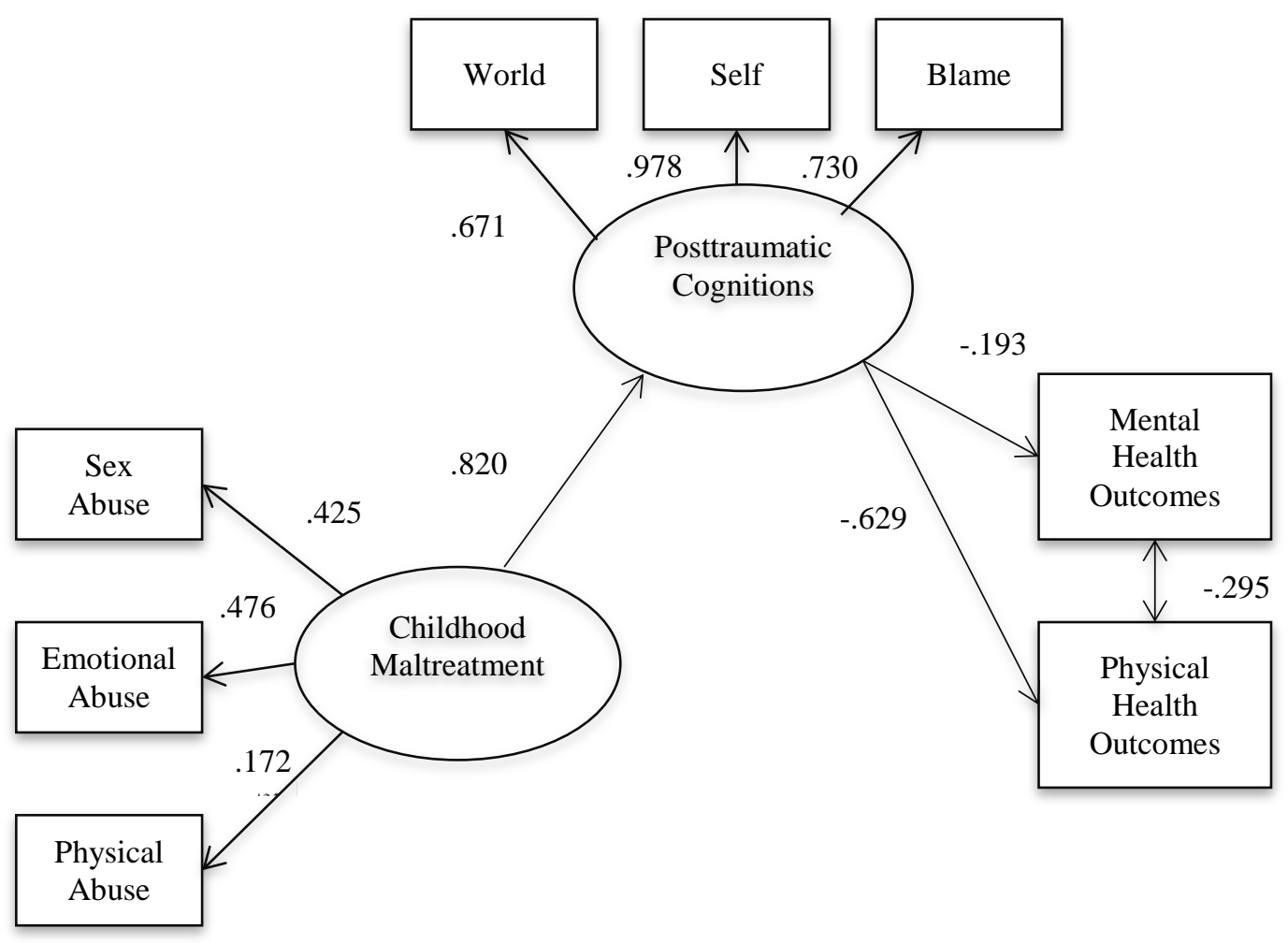




\section{APPENDICES}

\section{INFORMED CONSENT FORM}

University of Rhode Island

Department of Psychology

Title of research project: Childhood Maltreatment, Posttraumatic Cognitions and Health Outcomes Among Young Adults

You have been invited to take part in the research project described below. If you have any questions, please feel free to call or email Elizabeth Reichert, MA (978979-0596; ereichert@my.uri.edu) or Ellen Flannery-Schroeder, PhD (401-874-4219; efschroeder@uri.edu), the people mainly responsible for this study.

1. Description of the project: The purpose of this study is to better understand the long-term effects of childhood maltreatment. Child maltreatment includes any act that harms a person under the age of 18. Such acts of harm include: physical, emotional, or sexual abuse, and physical or emotional neglect. You may take part in this study whether or not you have ever experienced maltreatment of any kind.

Childhood maltreatment is often associated with many negative mental and physical health consequences. This study is attempting to better understand this link by learning more about what young adults think about themselves and others. We also want to learn about emotional difficulties young adults might be experiencing, like feeling nervous or sad, or physical health difficulties, such as experiencing pain or limited activity due to health problems.

2. What will be done: If you agree to take part in this project, you will be one of about 700 college student who will be asked to complete the following survey that asks about your experiences as a child, perceptions about yourself and others, current emotional or physical health difficulties, and related subject matter.

To participate, you must be at least 18 years of age, be able to read and speak English, and access this study on a computer with internet access. This study is conducted entirely online and should take approximately 15-35 minutes to complete.

If you participate, you will have the option to be entered into a lottery for one of the following giftcards: five $\$ 10$ iTunes giftcards, five \$10 Dunkin' Donuts giftcards, and one $\$ 50$ Visa giftcard. In order to be entered into the lottery, you will have to provide an email address but there will be no way to link your email address to your answers on the survey. At the end of the survey, you will click on a link to a separate survey, where you can submit your contact information for the lottery.

3. Possible risks or discomforts: While the possible risks and/or discomforts of this study are minimal, it is possible for you to feel some distress or discomfort while answering questions about your experiences as a child, especially if you experienced maltreatment in the past. 
4. Expected study benefits: Although there are no direct personal benefits of the study, your answers will help increase the knowledge regarding the long-term effects of childhood maltreatment and what factors may play a role in the development of negative health consequences in adulthood. Importantly, this information will help to develop better interventions aimed at improving healthy functioning among young adults who have experienced maltreatment as a child.

5. Confidentiality: Importantly, your part in this study is completely anonymous. That means that your answers to all questions are completely private. We will not know who provided which responses, and we will therefore not be able to trace your responses back to you.

No one else can know if you participated in this study and no one else can find out what your answers were. Scientific reports will be based on group data and will not identify you or any individual as being in this project. Your responses to assessment questions will be stored in a secure database on a server of the company that is hosting the internet survey (SurveyMonkey.com) and no identifying information will be included. We will not collect or store IP addresses. After online data collection is complete, the anonymous data will be transferred to the study investigator's computer and will remain password protected to ensure only the study investigator will have access to it.

6. Decision to quit at any time: Taking part in this project is completely up to you. You do not have to participate and you can refuse to answer any question.

You will be allowed to discontinue the survey at any time and you do not need to give any reasons for discontinuation.

7. Rights and complaints: Participation in this study is not expected to be harmful or injurious to you. However, if this study causes you any injury you should write or call the people in charge of this study at the University of Rhode Island, Elizabeth Reichert, MA and Dr. Ellen Flannery-Schroeder (401-874-4219). If you have other concerns about this study or if you have questions about your rights as a research participant, you may contact the University of Rhode Island's Vice President for Research, 70 Lower College Road, Suite 2, URI, Kingston, RI, (401) 874-4328.

If any of these questions are upsetting and you would like to speak with someone, please do not hesitate to use the following phone numbers:

University of Rhode Island Counseling Center: (401) 874-2288

The Psychological Consultation Center (Washburn Hall): (401) 874-4263

You are at least 18 years old. You have read the consent form and your questions have been answered to your satisfaction. You understand that you may ask any additional questions at any time and that your participation in this project is voluntary. Your filling out the survey implies your consent to participate in this study. If you would like a copy of this form, please print it out before continuing.

Thank you in advance for your time, 


\section{Clinical Psychology Doctoral Student}

Ellen Flannery-Schroeder, PhD

Principle Investigator

I have read, understood, and printed a copy of, the above consent form and desire of my own free will to participate in this study.

Yes or No 


\section{$\underline{\text { Demographics Questions }}$}

Please answer the following questions as accurately as possible. Your answers will remain anonymous.

1.Please indicate your sex: Male or Female

2.Please indicate your age: (range 18-65)

3.Please indicate your race/ethnicity:

4.African American/Black, Asian/Pacific Islander, American Indian/Alaska Native, White, Other: specify

5.Hispanic/Latino: Yes, No

6.Please indicate your marital status: Single, Married, Divorced, Separated, Widowed, Other: specify

7.Please indicate your religion: Catholic, Protestant, Jewish, Muslim, Atheist, Agnostic, Other: specify

8.What year are you in school: Freshman, Sophomore, Junior, Senior, Other: specify

9.Do you currently live: On campus? Off campus?

10.Please indicate your employment status: Employed full-time, Employed parttime, Unemployed

11.Do you currently have health insurance? Yes, No

If yes, do you currently use the health insurance plan offered by URI? Yes, No

1.Please indicate your personal annual income: $\$ 0-4,999 ; \$ 5,000-9,999 ; \$ 10,000$ -

19,999; \$20,000-29,999; \$30,000-39,000; \$40,000-49,000; \$50,000-59,999,

\$60,000-69,999, \$70,000-79,999, \$80,000-89,999, \$90,000-99,999, \$100,000-

$149,000, \$ 150,000+$

2.Please indicate your parents' employment status:

3.Mother: Employed full-time, Employed part-time, Unemployed

4.Father: Employed full-time, Employed part-time, Unemployed

5.Please indicate your family's annual income: $\$ 0-4,999 ; \$ 5,000-9,999 ; \$ 10,000$ -

19,999; \$20,000-29,999; \$30,000-39,000; \$40,000-49,000; \$50,000-59,999, $\$ 60,000-69,999, \$ 70,000-79,999, \$ 80,000-89,999$, \$90,000-99,999, \$100,000$149,000, \$ 150,000+$

6.Please indicate your parents' marital status: Single, Married, Divorced, Separated, Widowed, Other: specify 
7.Please indicate your mother's highest level of education: Some High School, High School degree, Some College, College Degree, Associates Degree, Graduate School 8.Please indicate your father's highest level of education: less than High School, High School degree/GED, Some College, Two-Year Degree (Associates), FourYear College Degree (BA, BS), Some Graduate Work; Masters Degree (MA, MS); Professional Degree (MD, JD); Advanced Graduate work or PhD

9.Please indicate if your parents have ever had any health/medical problems: Yes, No

10.If yes, please describe: ; How long: (mother)

11.If yes, please describe: ; How long: (father)

12.Please indicate if your parents have ever had any emotional or mental health problems: Yes, No

13.If yes, please describe: ; How long: (mother)

14.If yes, please describe: ; How long: (father) 
Age: Sex:

\begin{tabular}{|c|c|c|c|c|c|}
\hline & 1 & 2 & 3 & 4 & 5 \\
\hline 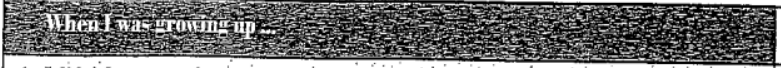 & $\begin{array}{c}\text { Never } \\
\text { True } \\
\end{array}$ & $\begin{array}{l}\text { Rarely } \\
\text { True }\end{array}$ & \begin{tabular}{|c|} 
Sometimes \\
Tine \\
\end{tabular} & $\begin{array}{l}\text { Often } \\
\text { True }\end{array}$ & $\begin{array}{c}\text { Very Otten } \\
\text { True }\end{array}$ \\
\hline 1. I didn't have enough to est & - & - & 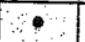 & - & 0 \\
\hline 2. I bnew that there was someone to take care of me and protect me. $(R)$ & $\bullet$ & - & - & - & $\bullet$ \\
\hline 3. People in my family called me things like "stupid," "lazy," or "ugly," & 0 & 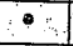 & - & - & 6 \\
\hline 4. My parents were too drunk or high to take care of the family. & - & - & - & - & - \\
\hline 5. There was someone in wy family who helped me feel that I was important or special. (R) & - & $\bullet$ & $\bullet$ & $\bullet$ & $\bullet$ \\
\hline 6. I had to wear dirty clothes. & • & $\bullet$ & $\bullet$ & - & • \\
\hline 7. Feltloved. $(2)$ & $\bullet$ & - & 0 & $\bullet$ & - \\
\hline 8. I thought that my parents wished I bad never been born. & • & 6 & - & • & • \\
\hline 9. I got hit so hard by someone in my family that $I$ had to see a doctor or go to the hospital. & 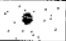 & 0 & 6 & -1 & $\therefore$ \\
\hline 10. There was nothing I wanted to change about my family. (A) & • & • & $\bullet$ & • & • \\
\hline 11. People in my family hit me so hard that it left me with bruises or marks. & $\bullet$ & 0 & -1 & 6 & 0 \\
\hline 12. I was punished with a belt, a board, a cord, or some other hard object. & - & - & - & - & - \\
\hline 13. People in my family looked out for each other is (R) & 6 & - : & 6 & $\bullet$ & 6 \\
\hline 14. People in my family said hurtful or insulting things to me. & - & $\cdot$ & - & • & $\bullet$ \\
\hline 15. I believe that I was physically abused $p$ & $\bullet$ & - & -1 & $\bullet$ & $\because$ \\
\hline 16. I had the perfect childhood. (C) & $\bullet$ & • & - & - & $\bullet$ \\
\hline 17. I got hit or beaten so badly that it was noticed by someone like a teacher, neighbor, or doctor. & 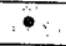 & $?$ & - & 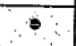 & 6 \\
\hline 18. If felt that someone in my family hated me. & - & 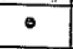 & $\bullet$ & - & • \\
\hline 19. People in my fanily felt close to each other (R) & - & 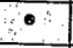 & 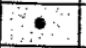 & $\therefore \cdots$ & - \\
\hline 20. Someone tried to touch me in a serral way or tried to make-me touch then & $\bullet$ & - & $\bullet$ & - & - \\
\hline 21. Someone threatened to burtme or tell lies ebout me unless I did something sexual with themy & $\bullet$ & - & $\bullet$ & 0 & - \\
\hline 22. I had the best family in the world. & - & • & • & - & $\bullet$ \\
\hline 23. Someone tried to make me do sexual things or watch sexual things. & $\bullet$ & a & $\bullet$ & 0 & $\bullet$ \\
\hline 24. Someone molested me & $\bullet$ & - & $\bullet$ & • & $\bullet$ \\
\hline 25. I believe that I was emotionally abused. & •. & - & - & - & $\bullet$ \\
\hline 26. There was someone to take me to the doctor if I needed it. & $\bullet$ & • & • & • & $\bullet$ \\
\hline 27. Fbelieve tbat I was sexually abused. & - & $\bullet$ & $\bullet$ & $\bullet$ & $\bullet$ \\
\hline 28. My family was a source of strength and support $(R)$ & $\bullet$ & $\bullet$ & $\bullet$ & - & $\bullet$ \\
\hline
\end{tabular}

Emotionel Abuse

Physical Abuese

arainia Sex Abuse

- Eno reqlect

phys. neglect 
Appendix A

Posttraumatic Cognitions Inventory (PTCI)

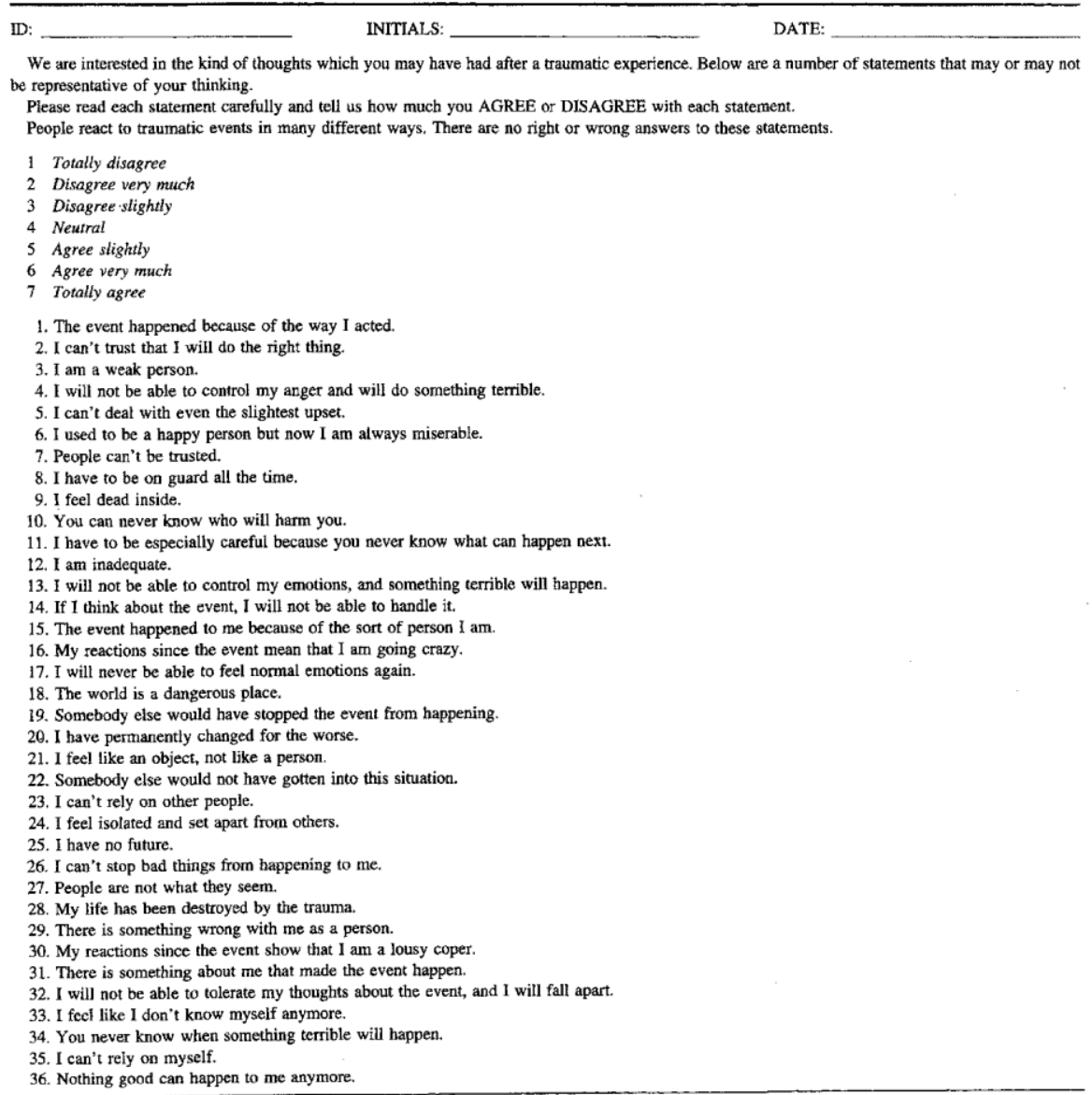

(Appendixes continue) 


\section{Your Health and Well-Being}

This survey asks for your views about your health. This information will help keep track of how you feel and how well you are able to do your usual activities. Thank you for completing this survey!

For each of the following questions, please mark an $\triangle$ in the one box that best describes your answer.

1. In general, would you say your health is:

\begin{tabular}{|ccccc|}
\hline Excellent & $\begin{array}{c}\text { Very } \\
\text { good }\end{array}$ & Good & Fair & Poor \\
$\square_{1}$ & $\nabla$ & $\nabla$ & $\nabla$ & $\nabla$ \\
$\square_{2}$ & $\square_{3}$ & $\square_{4}$ & $\square_{5}$
\end{tabular}

2. Compared to one year ago, how would you rate your health in general now?

\begin{tabular}{ccccc|}
$\begin{array}{c}\text { Much better } \\
\text { now than } \\
\text { one year } \\
\text { ago }\end{array}$ & $\begin{array}{c}\text { Somewhat } \\
\text { better } \\
\text { now than one } \\
\text { year ago }\end{array}$ & $\begin{array}{c}\text { About the } \\
\text { same as } \\
\text { one year } \\
\text { ago }\end{array}$ & $\begin{array}{c}\text { Somewhat worse } \\
\text { now than one } \\
\text { year ago }\end{array}$ & $\begin{array}{c}\text { Much } \\
\text { worse } \\
\text { now than } \\
\text { one year } \\
\text { ago }\end{array}$ \\
$\square_{2}$ & $\square_{3}$ & $\square_{4}$ &
\end{tabular}


3. The following questions are about activities you might do during a typical day. Does your health now limit you in these activities? If so, how much?

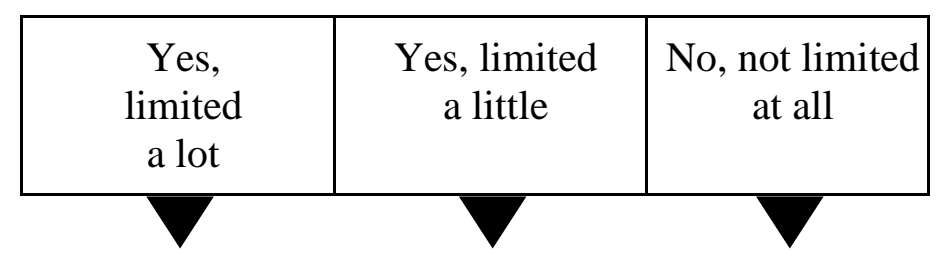

Vigorous activities, such as running, lifting heavy objects, participating in strenuous sports

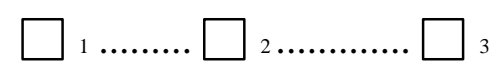

$\downarrow$ Moderate activities, such as moving a table, pushing a vacuum cleaner, bowling, or playing golf

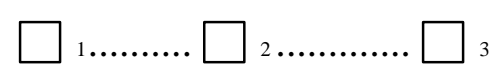

Lifting or carrying groceries

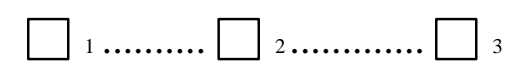

¿Climbing several flights of stairs

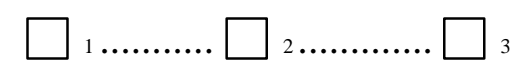

¿Climbing one flight of stairs

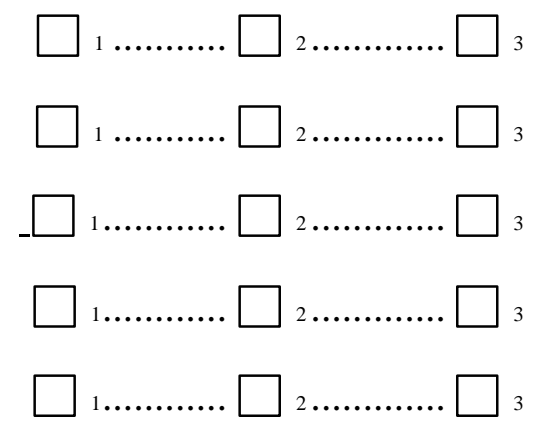

jBathing or dressing yourself

ÆBending, kneeling, or stooping

${ }_{\mathrm{g}}$ Walking more than a mile

${ }_{\mathrm{h}}$ Walking several hundred yards

iWalking one hundred yards

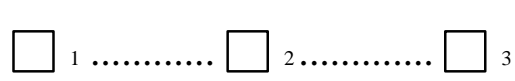


4. During the past 4 weeks, how much of the time have you had any of the following problems with your work or other regular daily activities as a result of your physical health?

$\begin{array}{|cccc|}\begin{array}{c}\text { All of } \\ \text { the time }\end{array} & \begin{array}{c}\text { Most of } \\ \text { the time }\end{array} & \begin{array}{c}\text { Some of } \\ \text { the time }\end{array} & \begin{array}{c}\text { A little of None of } \\ \text { the time the time }\end{array}\end{array}$

aCut down on the amount of time you spent on work or other activities

¿Accomplished less than you would like.

cWere limited in the kind of work or other activities<smiles>[AlH2]</smiles><smiles>[AlH2]</smiles><smiles>[Te]C1CCCC1</smiles>

dHad difficulty performing the work or other activities (for example, it took extra effort)

5. During the past 4 weeks, how much of the time have you had any of the following problems with your work or other regular daily activities as a result of any emotional problems (such as feeling depressed or anxious)?

Cut down on the amount of

$\begin{array}{|cccc|}\begin{array}{c}\text { All of } \\ \text { the time }\end{array} & \begin{array}{c}\text { Most of } \\ \text { the time }\end{array} & \begin{array}{c}\text { Some of } \\ \text { the time }\end{array} & \begin{array}{c}\text { A little of } \\ \text { the time }\end{array}\end{array}$
time you spent on work or other activities<smiles>C1CCC1</smiles><smiles>Oc1ccco1</smiles>

¿Accomplished less than you would like.

¿Did work or other activities less carefully than usual. 
6. During the past 4 weeks, to what extent has your physical health or emotional problems interfered with your normal social activities with family, friends, neighbors, or groups?

\begin{tabular}{|ccccc|}
\hline Not at all & Slightly & Moderately & Quite a bit & Extremely \\
$\square_{1}$ & $\nabla$ & $\nabla$ & $\nabla$ & $\nabla$ \\
$\square_{2}$ & $\square_{3}$ & $\square_{4}$ & $\square_{5}$
\end{tabular}

7. How much bodily pain have you had during the past 4 weeks?

\begin{tabular}{|cccccc|}
\hline None & Very mild & Mild & Moderate & Severe & Very severe \\
$\square_{1}$ & $\square_{2}$ & $\square_{3}$ & $\square_{4}$ & $\square_{5}$ & $\square_{6}$
\end{tabular}

8. During the past 4 weeks, how much did pain interfere with your normal work (including both work outside the home and housework)?

\begin{tabular}{|lcccc|}
\hline Not at all & A little bit & Moderately & Quite a bit & Extremely \\
$\square_{1}$ & $\square_{2}$ & $\square_{3}$ & $\square_{4}$ & $\square_{5}$
\end{tabular}




\section{These questions are about how you feel and how things have been} with you during the past 4 weeks. For each question, please give the one answer that comes closest to the way you have been feeling. How much of the time during the past 4 weeks...
All of
Most of
Some of
A little of None of the time the time the time the time the time
Did you feel full of life?
$\square$

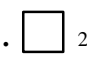
b Have you been very nervous?

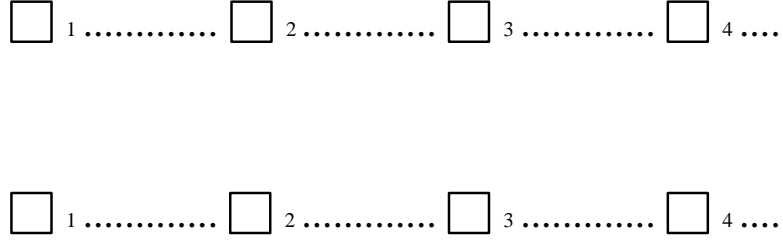
c Have you felt so down in the dumps that nothing could cheer you up?
d Have you felt calm and peaceful?
e Did you have a lot of energy?
Have you felt downhearted and depressed?
g Did you feel worn out?
h Have you been happy?
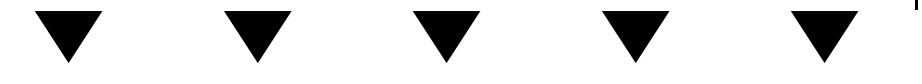


\section{How TRUE or FALSE is each of the following statements for you?}

\begin{tabular}{|ccccc|}
\hline $\begin{array}{c}\text { Definitely } \\
\text { true }\end{array}$ & $\begin{array}{c}\text { Mostly } \\
\text { true }\end{array}$ & $\begin{array}{c}\text { Don't } \\
\text { know }\end{array}$ & $\begin{array}{c}\text { Mostly } \\
\text { false }\end{array}$ & $\begin{array}{c}\text { Definitely } \\
\text { false }\end{array}$ \\
\hline & $\nabla$ & $\nabla$ & &
\end{tabular}

a seem to get sick a little

easier than other people.

$\square$

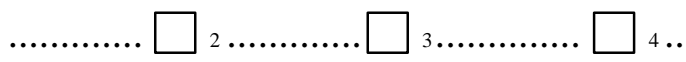

${ }_{b} \mathrm{I}$ am as healthy as anybody I know
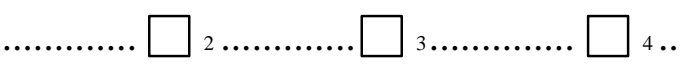

cI expect my health to

get worse
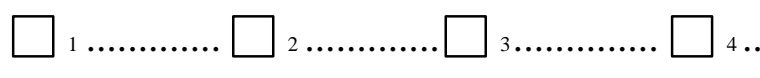

${ }_{\mathrm{d}} \mathrm{My}$ health is excellent<smiles>C1=CCCC1</smiles> 


\section{Health Care Utilization Questionnaire}

(modified from Newman, 1998)

Since September (approximately six months ago), have you seen a health professional about your mental or physical health?"

Yes or No

If yes, please indicate the type of visit and number of visits by circling the number that best corresponds to the scale below.

$\mathbf{1}=1-3$ visits $\quad \mathbf{2}=4-6$ visits $\quad \mathbf{3}=7-9$ visits $\quad \mathbf{4}=10-12$ visits $\quad \mathbf{5}=$ more than 12 visits

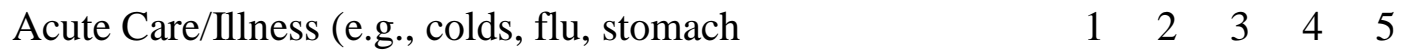
bug)

Routine Care (e.g., check ups)

$\begin{array}{lllll}1 & 2 & 3 & 4 & 5\end{array}$

Emergency/Urgent Care

$\begin{array}{lllll}1 & 2 & 3 & 4 & 5\end{array}$

Psychiatric Visits

$\begin{array}{lllll}1 & 2 & 3 & 4 & 5\end{array}$

Please rate how confident you are that the numbers you indicated above are accurate on a scale of 1-10:

\begin{tabular}{|c|c|}
\hline t at all & 2 \\
\hline
\end{tabular}




\section{Posttraumatic Stress Diagnostic Scale (PDS)}

\section{Subject ID:}

\section{Part 1}

Many people have lived through or witnessed a very stressful and traumatic event at some point in their lives. Below is a list of traumatic events. Put an "X" on the line next to ALL of the events that have happened to you or that you have witnessed.

1. ___ Serious accident, fire, or explosion (for example, an industrial, farm, car, plane, or boating accident)

2. ___ Natural disaster (for example, tornado, hurricane, flood, or major earthquake)

3. ___ Non-sexual assault by a family member or someone you know (for example, being mugged, physically attacked, shot, stabbed, or held at gunpoint)

4. N_ Non-sexual assault by a stranger (for example, being mugged, physically attacked, shot, stabbed, or held at gunpoint)

5. ___ Sexual assault by a family member or someone you know (for example, rape or attempted rape)

6. ___ Sexual assault by a stranger (for example, rape, or attempted rape)

7. ___ Military combat or a war zone

8. ___ Sexual contact when you were younger than 18 with someone who was 5 or more years older than you (for example, contact with genitals, breasts)

9. ___ Imprisonment (for example, prison inmate, prisoner or war, hostage)

10. Torture

11. ___ Life-threatening illness

12. Other traumatic event

13. If you marked item 12 , specify the traumatic event below

IF YOU MARKED ANY OF THE ITEMS ABOVE, CONTINUE. IF NOT STOP HERE. 
Posttraumatic Stress Diagnostic Scale (PDS)

\section{PART 2}

14. If you marked more than one traumatic event in Part 1 , put an " $X$ " on the line below next to the event that bothers you the most. If you marked only one traumatic event in Part 1, mark the same one below.

Accident

Disaster

Non-sexual assault / someone you know

Non-sexual assault / stranger

Sexual assault / someone you know

Sexual assault / stranger

Combat

Sexual contact under 18 with someone 5 or more years older

Imprisonment

Torture

Life-Threatening illness

Other

Briefly describe the traumatic event you marked above

Below are several questions about the traumatic event you just described above.

15. How long ago did the traumatic event happen? (Circle one)

$\begin{array}{ll}1 & \text { Less than } 1 \text { month } \\ 2 & 1 \text { to } 3 \text { months } \\ 3 & 3 \text { to } 6 \text { months } \\ 4 & 6 \text { months to } 3 \text { years } \\ 5 & 3 \text { to } 5 \text { years } \\ 6 & \text { More than } 5 \text { years }\end{array}$

For the following questions, circle $\mathrm{Y}$ for "Yes" or $\mathrm{N}$ for "No".

During this traumatic event:
16. $\mathrm{Y} N$ Were you physically injured?
17. $\mathrm{Y}$ N Was someone else physically injured?
18. $\mathrm{Y} \mathrm{N}$ Did you think that your life was in danger?
19. $\mathbf{Y} \mathbf{N}$ Did you think that someone else's life was in danger?
20. $\mathrm{Y} \quad \mathrm{N}$ Did you feel helpless?
21. $\mathbf{Y} \mathbf{N}$ Did you feel terrified? 
Posttraumatic Stress Diagnostic Scale (PDS)

\section{Part 3}

Below is a list of problems that people sometimes have after experiencing a traumatic event. Read each one carefully and circle the number (0-3) that best describes how often that problem has bothered you IN THE PAST MONTH. Rate each problem with respect to the traumatic even you described in Item 14

0 Not at all or only one time

Once a week or less / once in a while

2 to 4 times a week / half the time

5 or more times a week / almost always

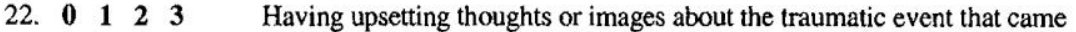
into your head when you didn't want them to

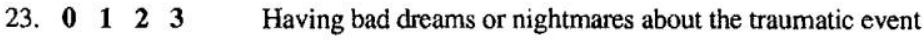

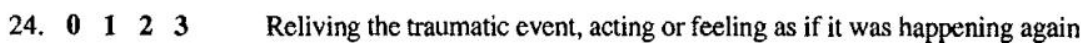

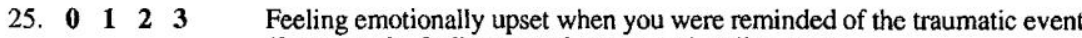
(for example, feeling scared, angry, sad, guilty, etc.)

26. $\begin{array}{llllll} & 1 & 2 & 3 & \text { Experiencing physical reactions when you were reminded of the traumatic }\end{array}$ event (for example, breaking out in a sweat, heart beating fast)

27. $\begin{array}{lllll} & 1 & 2 & 3 & \text { Trying not to think about, talk about, or have feelings about the traumatic }\end{array}$ event

28. $\begin{array}{lllll} & 1 & 2 & 3 & \text { Trying to avoid activities, people or places that remind you of the traumatic }\end{array}$ event

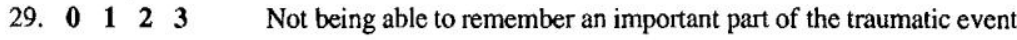

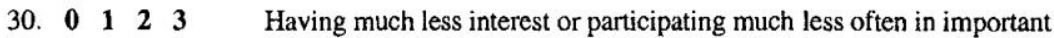
activities

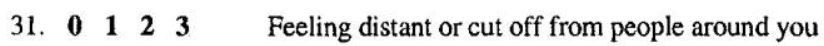

32. 01223 Feeling emotionally numb (for example, being unable to cry or unable to have loving feelings)

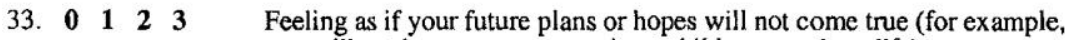
you will not have a career, marriage, children, or a long life)

34. $\begin{array}{llllll} & 1 & 2 & 3 & \text { Having trouble falling or staying asleep }\end{array}$

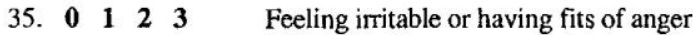


Posttraumatic Stress Diagnostic Scale (PDS)

(Part 3 - continued)

Not at all or only one time

Once a week or less / once in a while

2 to 4 times a week / half the time

5 or more times a week / almost always

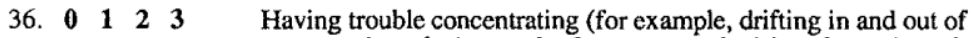
conversations, losing track of a story on television, forgetting what you read)

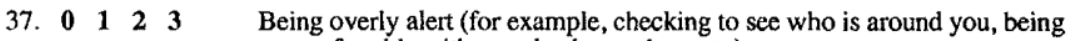
uncomfortable with your back to a door, etc)

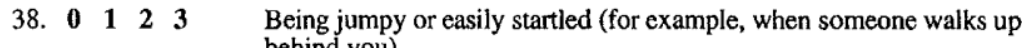
behind you)

39. How long have you experienced the problems that you reported above? (Circle one)

$1 \quad$ Less than 1 month

21 to 3 months

3 More than 3 months

40. How long after the traumatic event did these problems begin? (Circle one)

1 Less than 6 months

26 or more months 


\section{Posttraumatic Stress Diagnostic Scale (PDS)}

\section{Part 4}

Indicate below if the problems you rated in Part 3 have interferred with any of the following areas of you life DURING THE PAST MONTH. Circle Y for "Yes" or N for "No".
41. $\mathbf{Y}$ N Work
42. $\mathbf{Y} \mathbf{N}$ Household chores and duties
43. $\mathbf{Y}$ N Relationships with friends
44. $\quad \mathbf{Y} \quad \mathbf{N}$ Fun and leisure activities
45. $\mathbf{Y}$ N Schoolwork
46. $\quad$ Y N Relationships with your family
47. $\mathbf{Y} \quad \mathbf{N}$ Sex life
48. $\mathrm{Y} \quad \mathrm{N}$ General satisfaction with life
49. $\mathbf{Y} \quad \mathbf{N}$ Overall level of functioning in all areas of your life 


\section{References}

Appleyard, K., Egeland, B., van Dulmen, M. H., \& Sroufe, L. A. (2005). When more is not better: The role of cumulative risk in child behavior outcomes. Journal of Child Psychology and Psychiatry, and Allied Disciplines, 46(3), 235-245. doi: 10.1111/j.1469-7610.2004.00351.x

Appleyard, K., Yang, C., \& Runyan, D. K. (2010). Delineating the maladaptive pathways of child maltreatment: A mediated moderation analysis of the roles of self-perception and social support. Development and Psychopathology, 22(2), 337-352. doi: 10.1017/S095457941000009X; 10.1017/S095457941000009X

Arnow, B. A. (2004). Relationships between childhood maltreatment, adult health and psychiatric outcomes, and medical utilization. The Journal of Clinical Psychiatry, 65 Suppl 12, 10-15.

Arnow, B. A., Hart, S., Scott, C., Dea, R., O'Connell, L., \& Taylor, C. B. (1999). Childhood sexual abuse, psychological distress, and medical use among women. Psychosomatic Medicine, 61(6), 762-770.

Banyard, V. L., Williams, L. M., \& Siegel, J. A. (2001). The long-term mental health consequences of child sexual abuse: An exploratory study of the impact of multiple traumas in a sample of women. Journal of Traumatic Stress, 14(4), $697-$ 715. doi:10.1023/A:1013085904337

Baron, R \& Kenney, D. (1986). The moderator-mediator variable distinction in social psychological research: Conceptual, strategic, and statistical considerations. Journal of Personality and Social Psychology, 51(6): 1173-1182. 
Beck, A. (1967). Depression: Causes and treatment. Philadelphia: University of Pennsylvania Press.

Beck, A. (1987). Cognitive models of depression. Journal of Cognitive Psychotherapy, 1, 5-37.

Beckham, J. C., Moore, S. D., Feldman, M. E., Hertzberg, M. A., Kirby, A. C., \& Fairbank, J. A. (1998). Health status, somatization, and severity of posttraumatic stress disorder in vietnam combat veterans with posttraumatic stress disorder. The American Journal of Psychiatry, 155(11), 1565-1569.

Bentler, P. (2000-2008). EQS 6 Structural Equation Program Manual. Los Angeles, CA: Software, Inc.

Bentler, P. (1990). Comparative fit indexes in structural models. Psychological Bulletin, 107, 238-246.

Benyamini, Y., Leventhal, H., \& Leventhal, E. A. (2004). Self-rated oral health as an independent predictor of self-rated general health, self-esteem and life satisfaction. Social Science \& Medicine (1982), 59(5), 1109-1116. doi: 10.1016/j.socscimed.2003.12.021

Bernstein, D.P, \& Fink, L. (1998). Childhood Trauma Questionnaire: A retrospective self-report manual San Antonio, TX: The Psychological Corporation.

Bernstein, D. P., Stein, J. A., Newcomb, M. D., Walker, E., Pogge, D., Ahluvalia, T.,Zule, W. (2003). Development and validation of a brief screening version of the childhood trauma questionnaire. Child Abuse \& Neglect, 27(2), 169-190.

Bonomi, A. E., Anderson, M. L., Rivara, F. P., Cannon, E. A., Fishman, P. A., Carrell, D., Thompson, R. S. (2008). Health care utilization and costs associated with 
childhood abuse. Journal of General Internal Medicine, 23(3), 294-299.

doi:10.1007/s11606-008-0516-1

Brazier, J. E., Harper, R., Jones, N. M., O'Cathain, A., Thomas, K. J., Usherwood, T., \& Westlake, L. (1992). Validating the SF-36 health survey questionnaire: New outcome measure for primary care. BMJ (Clinical Research Ed.), 305(6846), $160-164$.

Brewin, C. R., Andrews, B., \& Gotlib, I. H. (1993). Psychopathology and early experience: A reappraisal of retrospective reports. Psychological Bulletin, 113(1), $82-98$.

Brewin, C. R., \& Holmes, E. A. (2003). Psychological theories of posttraumatic stress disorder. Clinical Psychology Review, 23(3), 339-376.

Briere, J., \& Elliott, D. M. (2003). Prevalence and psychological sequelae of selfreported childhood physical and sexual abuse in a general population sample of men and women. Child Abuse \& Neglect, 27(10), 1205-1222.

Briere, J., Woo, R., McRae, B., Foltz, J., \& Sitzman, R. (1997). Lifetime victimization history, demographics, and clinical status in female psychiatric emergency room patients. The Journal of Nervous and Mental Disease, 185(2), 95-101.

Brown, G. R., \& Anderson, B. (1991). Psychiatric morbidity in adult inpatients with childhood histories of sexual and physical abuse. The American Journal of Psychiatry, 148(1), 55-61.

Buckingham, E. T., \& Daniolos, P. (2013). Longitudinal outcomes for victims of child abuse. Current Psychiatry Reports, 15(2), 342-012-0342-3. doi: 10.1007/s11920012-0342-3; 10.1007/s11920-012-0342-3 
Chartier, M. M. J. (2007). Childhood abuse, adult health, and health care utilization: Results from a representative community sample. American Journal of Epidemiology, 165(9), 1031-1038.

Chartier, M. J., Walker, J. R., \& Naimark, B. (2009). Health risk behaviors and mental health problems as mediators of the relationship between childhood abuse and adult health. American Journal of Public Health, 99(5), 847-854. doi:10.2105/AJPH.2007.122408

Chartier, M. J., Walker, J. R., \& Naimark, B. (2010). Separate and cumulative effects of adverse childhood experiences in predicting adult health and health care utilization. Child Abuse \& Neglect,34(6), 454-464.

doi:10.1016/j.chiabu.2009.09.020

Coker, A. L., Smith, P. H., Bethea, L., King, M. R., \& McKeown, R. E. (2000). Physical health consequences of physical and psychological intimate partner violence. Archives of Family Medicine, 9(5), 451-457.

Coyne, J. C., \& Gotlib, I. H. (1983). The role of cognition in depression: A critical appraisal. Psychological Bulletin, 94(3), 472-505.

Davis, D. A., Luecken, L. J., \& Zautra, A. J. (2005). Are reports of childhood abuse related to the experience of chronic pain in adulthood? A meta-analytic review of the literature. The Clinical Journal of Pain, 21(5), 398-405.

Davis, J., Combs-Lane, A., \& Smith, D. (2004). Victimization and health risk behaviors: Implications for prevention programs. In K. Kendall-Tackett (Ed.), Health consequences of abuse in the family: A clinical guide for evidence- 
based practice (pp. 179-195). Washington, DC: American Psychological Association.

Drossman, D. A., Leserman, J., Nachman, G., Li, Z. M., Gluck, H., Toomey, T. C., \& Mitchell, C. M. (1990). Sexual and physical abuse in women with functional or organic gastrointestinal disorders. Annals of Internal Medicine, 113(11), 828-833.

Dunmore, E., Clark, D. M., \& Ehlers, A. (1999). Cognitive factors involved in the onset and maintenance of posttraumatic stress disorder (PTSD) after physical or sexual assault. Behaviour Research and Therapy, 37(9), 809-829. doi:10.1016/S0005-7967(98)00181-8

Edwards, V. J., Holden, G. W., Felitti, V. J., \& Anda, R. F. (2003). Relationship between multiple forms of childhood maltreatment and adult mental health in community respondents: Results from the adverse childhood experiences study. The American Journal of Psychiatry, 160(8), 1453-1460.

Ehlers, A., \& Clark, D. (2003). Early psychological interventions for adult survivors of trauma: A review. Biological Psychiatry, 53(9), 817-826.

Ehlers, A., \& Clark, D. M. (2000). A cognitive model of posttraumatic stress disorder. Behaviour Research and Therapy, 38(4), 319-345. doi:10.1016/S00057967(99)00123-0

Elhai, J. D., North, T. C., \& Frueh, B. C. (2005). Health service use predictors among trauma survivors: A critical review. Psychological Services, 2(1), 3-19. doi:10.1037/1541-1559.2.1.3

Fang, X., Brown, D. S., Florence, C. S., \& Mercy, J. A. (2012). The economic burden of child maltreatment in the united states and implications for prevention. Child 
Abuse \& Neglect, 36(2), 156-165. doi: 10.1016/j.chiabu.2011.10.006;

10.1016/j.chiabu.2011.10.006

Felitti, V. J., Anda, R. F., Nordenberg, D., Williamson, D. F., Spitz, A. M., Edwards, V., Marks, J. S. (1998). Relationship of childhood abuse and household dysfunction to many of the leading causes of death in adults. the adverse childhood experiences (ACE) study. American Journal of Preventive Medicine, 14(4), 245-258.

Fergusson, D. M., Boden, J. M., \& Horwood, L. J. (2008). Exposure to childhood sexual and physical abuse and adjustment in early adulthood. Child Abuse \& Neglect, 32(6), 607-619. doi:10.1016/j.chiabu.2006.12.018

Finestone, H. M., Stenn, P., Davies, F., Stalker, C., Fry, R., \& Koumanis, J. (2000). Chronic pain and health care utilization in women with a history of childhood sexual abuse. Child Abuse \& Neglect, 24(4), 547-556.

Finkelhor, D. (1994). Current information on the scope and nature of child sexual abuse. The Future of Children / Center for the Future of Children, the David and Lucile Packard Foundation, 4(2), 31-53.

Finkelhor, D., Ormrod, R., Turner, H., \& Hamby, S. L. (2005). The victimization of children and youth: A comprehensive, national survey. Child Maltreatment, 10(1), 5-25. doi: $10.1177 / 1077559504271287$

Foa, E., \& Rothbaum, B. (1998). Treating the trauma of rape: Cognitive behavioral therapy for PTSD. New York, New York: Guilford Press. 
Foa, E., \& Riggs, D. (1993). Post-traumatic stress disorder in rape victims. In J. Oldham, M. Riba \& A. Tasman (Eds.), American psychiatric press review of psychiatry (pp. 273-303). Washington, DC: American Psychiatric Press.

Foa, E., Steketee, G., \& Rothbaum, B. (1989). Behavioral/cognitive conceptualizations of posttraumatic stress. Behavior Therapy, 20, 155-176.

Foa, E. B., Cashman, L., Jaycox, L., \& Perry, K. (1997). The validation of a selfreport measure of posttraumatic stress disorder: The posttraumatic diagnostic scale. Psychological Assessment, 9(4), 445-451. doi:10.1037/1040-3590.9.4.445

Foa, E. B., Ehlers, A., Clark, D. M., Tolin, D. F., \& Orsillo, S. M. (1999). The posttraumatic cognitions inventory (PTCI): Development and validation. Psychological Assessment, 11(3), 303-314. doi:10.1037/10403590.11.3.303

Frazier, P. A. (2003). Perceived control and distress following sexual assault: A longitudinal test of a new model. Journal of Personality and Social Psychology, 84(6), 1257-1269.

Gabbay, V., Oatis, M.D,, Silva, R.R. \& Hirsch, G. (2004). Epidemiological aspects of PTSD in children and adolescents. In Raul R. Silva (Ed.), Posttraumatic stress disorder in children and adolescents: Handbook. (1-17). New York: Norton.

Gibb, B. E., Alloy, L. B., Abramson, L. Y., Rose, D. T., Whitehouse, W. G., Donovan, P., Tierney, S. (2001). History of childhood maltreatment, negative cognitive styles, and episodes of depression in adulthood. Cognitive Therapy and Research, 25(4), 425-446. doi:10.1023/A:1005586519986 
Gilbert, R., Widom, C. S., Browne, K., Fergusson, D., Webb, E., \& Janson, S. (2009). Burden and consequences of child maltreatment in high-income countries. Lancet, 373(9657), 68-81. doi:10.1016/S0140-6736(08)61706-7

Gold, E. R. (1986). Long-term effects of sexual victimization in childhood: An attributional approach. Journal of Consulting and Clinical Psychology, 54(4), 471-475. doi:10.1037/0022-006X.54.4.471

Golding, J. M. (1994). Sexual assault history and physical health in randomly selected los angeles women. Health Psychology : Official Journal of the Division of Health Psychology, American Psychological Association, 13(2), 130-138.

Golding, J. M., Cooper, M. L., \& George, L. K. (1997). Sexual assault history and health perceptions: Seven general population studies. Health Psychology: Official Journal of the Division of Health Psychology, American Psychological Association, 16(5), 417-425.

Golding, J. M. (1999). Sexual-assault history and long-term physical health problems: Evidence from clinical and population epidemiology. Current Directions in Psychological Science, 8(6), 191-194. doi:10.1111/1467-8721.00045

Goodwin, R. D., Fergusson, D. M., \& Horwood, L. J. (2005). Childhood abuse and familial violence and the risk of panic attacks and panic disorder in young adulthood. Psychological Medicine, 35(6), 881-890.

Gould, D. A., Stevens, N. G., Ward, N. G., Carlin, A. S., Sowell, H. E., \& Gustafson, B. (1994). Self-reported childhood abuse in an adult population in a primary care setting. prevalence, correlates, and associated suicide attempts. Archives of Family Medicine, 3(3), 252-256. 
Hager, A. D., \& Runtz, M. G. (2012). Physical and psychological maltreatment in childhood and later health problems in women: An exploratory investigation of the roles of perceived stress and coping strategies. Child Abuse \& Neglect, 36(5), 393-403. doi: 10.1016/j.chiabu.2012.02.002; 10.1016/j.chiabu.2012.02.002

Hulme, P. A. (2000). Symptomatology and health care utilization of women primary care patients who experienced childhood sexual abuse. Child Abuse \& Neglect, 24(11), 1471-1484.

Hussey, J. M., Chang, J. J., \& Kotch, J. B. (2006). Child maltreatment in the united states: Prevalence, risk factors, and adolescent health consequences. Pediatrics, 118(3), 933-942. doi:10.1542/peds.2005-2452

Jumper, S. A. (1995). A meta-analysis of the relationship of child sexual abuse to adult psychological adjustment. Child Abuse \& Neglect, 19(6), 715-728. doi:10.1016/0145-2134(95)00029-8

Kaysen, D., Scher, C. D., Mastnak, J., \& Resick, P. (2005). Cognitive mediation of childhood maltreatment and adult depression in recent crime victims. Behavior Therapy, 36(3), 235-244. doi:10.1016/S0005-7894(05)80072-3

Kendall-Tackett, K. (2003). Treating the lifetime health effects of childhood victimization. Kingston, New Jersey: Civic Research Institute.

Kendall-Tackett, K. A., \& Marshall, R. (1999). Victimization and diabetes: An exploratory study. Child Abuse \& Neglect, 23(6), 593-596.

Kendall-Tackett, K. A. (2000). Physiological correlates of childhood abuse: Chronic hyperarousal in PTSD, depression, and irritable bowel syndrome. Child Abuse \& Neglect, 24(6), 799-810. doi:10.1016/S0145-2134(00)00136-8 
Kendall-Tackett, K., \& Klest, B. (Eds.). (2010). Trauma, dissociation and health:

Causal mechanisms and multidimensional pathways. New York, New York: Routledge.

Kendler, K. S., Bulik, C. M., Silberg, J., Hettema, J. M., Myers, J., \& Prescott, C. A. (2000). Childhood sexual abuse and adult psychiatric and substance use disorders in women: An epidemiological and cotwin control analysis. Archives of General Psychiatry, 57(10), 953-959.

Kessler, R. C., Davis, C., Kendler, K. (1997). Childhood adversity and adult psychiatric disorder in US National Comorbidity Survey. Psychological Medicine, 27: 1101-1119. Doi: 10.1017/S0033291797005588.

Kessler, R. C., Sonnega, A., Bromet, E., Hughes, M., \& Nelson, C. B. (1995). Posttraumatic stress disorder in the national comorbidity survey. Archives of General Psychiatry, 52(12), 1048-1060.

Keyes, K. M., Eaton, N. R., Krueger, R. F., McLaughlin, K. A., Wall, M. M., Grant, B. F., \& Hasin, D. S. (2012). Childhood maltreatment and the structure of common psychiatric disorders. The British Journal of Psychiatry : The Journal of Mental Science, 200(2), 107-115. doi: 10.1192/bjp.bp.111.093062; 10.1192/bjp.bp.111.093062.

Kline, R. B. (2010) Principles and Practice of Structural Equation Modeling (3rd Edition). New York, NY: The Guilford Press.

Kovacs, M., \& Beck, A. T. (1978). Maladaptive cognitive structures in depression. The American Journal of Psychiatry, 135(5), 525-533. 
Lampe, A., Doering, S., Rumpold, G., Solder, E., Krismer, M., Kantner-Rumplmair, W., Sollner, W. (2003). Chronic pain syndromes and their relation to childhood abuse and stressful life events. Journal of Psychosomatic Research, 54(4), 361367.

Lipschitz, D. S., Rasmusson, A. M., Anyan, W., Cromwell, P., \& Southwick, S. M. (2000). Clinical and functional correlates of posttraumatic stress disorder in urban adolescent girls at a primary care clinic. Journal of the Academy of Child \& Adolescent Psychiatry, 39(9), 1104-1111.

MacKinnon, D. P. (2008). Introduction to Statistical Mediation Analysis. New York: Erlbaum.

McCann, I., \& Pearlman, L. (1990). Psychological trauma and the adult survivor: Theory, therapy, and transformation. New York, New York: Brunner/Mazel.

McCauley, J., Kern, D. E., Kolodner, K., Dill, L., \& Schroeder, A. F. (1997). Clinical characteristics of women with a history of childhood abuse: Unhealed wounds. JAMA: Journal of the American Medical Association, 277(17), 13621368. doi:10.1001/jama.277.17.1362

McGee, R. A., Wolfe, D. A., Yuen, S. A., Wilson, S. K., \& Carnochan, J. (1995). The measurement of maltreatment: A comparison of approaches. Child Abuse \& Neglect, 19(2), 233-249.

McHorney, C. A., Ware, J. E.,Jr, \& Raczek, A. E. (1993). The MOS 36-item shortform health survey (SF-36): II. psychometric and clinical tests of validity in measuring physical and mental health constructs. Medical Care, 31(3), 247-263. 
Miller, E. A., Green, A. E., Fettes, D. L., \& Aarons, G. A. (2011). Prevalence of maltreatment among youths in public sectors of care. Child Maltreatment, 16(3), 196-204. doi: 10.1177/1077559511415091; 10.1177/1077559511415091

Molnar, B. E., Buka, S. L., \& Kessler, R. C. (2001). Child sexual abuse and subsequent psychopathology: Results from the national comorbidity survey. American Journal of Public Health, 91(5), 753-760.

Mullen, P. E., Martin, J. L., Anderson, J. C., Romans, S. E., \& Herbison, G. P. (1996). The long-term impact of the physical, emotional, and sexual abuse of children: A community study. Child Abuse \& Neglect, 20(1), 7-21.

Newman, M. G. (1998). The construct validity of the medical questionnaire. Unpublished manuscript.

Neumann, D., Houskamp, B., Pollack, V., \& Briere, J. (1996). The longterm sequelae of childhood sexual abuse in women: A metaanalytic review. Child Maltreat., 1, 6-16.

Newman, M. G., Clayton, L., Zuellig, A., Cashman, L., Arnow, B., Dea, R., \& Taylor, C. B. (2000). The relationship of childhood sexual abuse and depression with somatic symptoms and medical utilization. Psychological Medicine, 30(5), 10631077.

Paivio, S. C., \& Cramer, K., M. (2004). Structure and reliability of the Childhood Truama Questionnaire in a Canadian undergraduate student sample. Childhood Abuse \& Neglect, 28, 889-904. 
Ponce, A. N., Williams, M. K., \& Allen, G. J. (2004). Experience of maltreatment as a child and acceptance of violence in adult intimate relationships: Mediating effects of distortions in cognitive schemas. Violence and Victims, 19(1), 97-108.

Repetti, R. L., Taylor, S. E., \& Seeman, T. E. (2002). Risky families: Family social environments and the mental and physical health of offspring. Psychological Bulletin, 128(2), 330-366.

Rief, W., Hiller, W., \& Margraf, J. (1998). Cognitive aspects of hypochondriasis and the somatization syndrome. Journal of Abnormal Psychology, 107(4), 587-595.

Rosenberg, D. A., \& Krugman, R. D. (1991). Epidemiology and outcome of child abuse. Annual Review of Medicine, 42, 217-224. doi:

10.1146/annurev.me.42.020191.001245

Sachs-Ericsson, N., Blazer, D., Plant, E. A., \& Arnow, B. (2005). Childhood sexual and physical abuse and the 1-year prevalence of medical problems in the national comorbidity survey. Health Psychology : Official Journal of the Division of Health Psychology, American Psychological Association, 24(1), 32-40. doi:10.1037/0278-6133.24.1.32

Sachs-Ericsson, N., Kendall-Tackett, K., \& Hernandez, A. (2007). Childhood abuse, chronic pain, and depression in the national comorbidity survey. Child Abuse \& Neglect, 31(5), 531-547. doi:10.1016/j.chiabu.2006.12.007

Sachs-Ericsson, N., Cromer, K., Hernandez, A., \& Kendall-Tackett, K. (2009). A review of childhood abuse, health, and pain-related problems: The role of psychiatric disorders and current life stress. Journal of Trauma \& Dissociation, 10(2), 170-188. doi:10.1080/15299730802624585 
Sarkar, N. N. (2010) Childhood Sexual Abuse and Its Impact on Women's Health. International Medical Journal, 17 (2): 107-112

Scher, C. D., Forde, D. R., McQuaid, J. R., \& Stein, M. B. (2004). Prevalence and demographic correlates of childhood maltreatment in an adult community sample. Child Abuse \& Neglect, 28(2), 167-180. doi: 10.1016/j.chiabu.2003.09.012

Smucker, M. R., Dancu, C., Foa, E. B., \& Niederee, J. L. (2002). Imagery rescripting: A new treatment for survivors of childhood sexual abuse suffering from posttraumatic stress. In R. L. Leahy, \& E. T. Dowd (Eds.), (pp. 294-310). New York, NY, US: Springer Publishing Co.

Smyth, J. M., Heron, K. E., Wonderlich, S. A., Crosby, R. D., \& Thompson, K. M. (2008). The influence of reported trauma and adverse events on eating disturbance in young adults. The International Journal of Eating Disorders, 41(3), 195-202. doi:10.1002/eat.20490

Steiger, J. (1998). A note on multiple sample extensions of the RMSEA fit index. Structural Equation Modeling, 5, 411-419.

Stein, M. B., \& Barrett-Connor, E. (2000). Sexual assault and physical health: Findings from a population-based study of older adults. Psychosomatic Medicine, 62(6), 838-843.

Tabachnick, B. G., and Fidell, L. S. (2007). Using Multivariate Statistics, 5th ed. Boston, MA: Allyn and Bacon.

Taft, C. T., Stern, A. S., King, L. A., \& King, D. W. (1999). Modeling physical health and functional health status: The role of combat exposure, posttraumatic stress 
disorder, and personal resource attributes. Journal of Traumatic Stress, 12(1), 323. doi: $10.1023 / \mathrm{A}: 1024786030358$

Tarquis, N. (2006). Neurobiological hypothesis relating to connections between psychopathy and childhood maltreatment. [Hypotheses neurobiologiques concernant les liens entre psychopathie et maltraitance infantile] L'Encephale, 32 (3 Pt 1), 377-384.

Turner, A., \& Paivio, S. C., (2002). Alexithymia as a transmission mechanism between childhood trauma, social anxiety, and limited social support. Poster presented at the American Psychological Association convention, Chicago, IL.

Tyrka, A. R., Wyche, M. C., Kelly, M. M., Price, L. H., \& Carpenter, L. L. (2009). Childhood maltreatment and adult personality disorder symptoms: Influence of maltreatment type. Psychiatry Research, 165(3), 281-287. doi:10.1016/j.psychres.2007.10.017

Wagner, A. W., Wolfe, J., Rotnitsky, A., Proctor, S. P., \& Erickson, D. J. (2000). An investigation of the impact of posttraumatic stress disorder on physical health. Journal of Traumatic Stress, 13(1), 41-55. doi: 10.1023/A:1007716813407

Walker, E. A., Gelfand, A., Katon, W. J., Koss, M. P., Von Korff, M., Bernstein, D., \& Russo, J. (1999). Adult health status of women with histories of childhood abuse and neglect. The American Journal of Medicine, 107(4), 332-339.

Ware JE, Kosinski M, \& Keller SD. (1994). SF 36 Physical and Mental Health Summary Scales: A User's Manual. Boston, MA: The Health Institute, New England Medical Center. 
Ware JE, Jr., Kosinski M, Bayliss MS, McHorney CA, Rogers WH, \& Raczek A. (1995). Comparison of methods for the scoring and statistical analysis of SF 36 Health Profile and Summary Measures: Summary of results from the Medical Outcomes Study. Medical Care, 33:AS264-AS279

Wenninger, K., \& Ehlers, A. (1998). Dysfunctional cognitions and adult psychological functioning in child sexual abuse survivors. Journal of Traumatic Stress, 11(2), 281-300. doi: 10.1023/A:1024451103931

White, H. R., \& Widom, C. S. (2003). Does childhood victimization increase the risk of early death? A 25-year prospective study. Child Abuse \& Neglect, 27(7), 841853.

Widom, C. S., White, H. R., Czaja, S. J., \& Marmorstein, N. R. (2007). Long-term effects of child abuse and neglect on alcohol use and excessive drinking in middle adulthood. Journal of Studies on Alcohol and Drugs, 68(3), 317-326.

Williamson, D. F., Thompson, T. J., Anda, R. F., Dietz, W. H., \& Felitti, V. (2002). Body weight and obesity in adults and self-reported abuse in childhood. International Journal of Obesity and Related Metabolic Disorders : Journal of the International Association for the Study of Obesity, 26(8), 10751082. doi:10.1038/sj.ijo.0802038

World Health Organization (WHO). (2006). Preventing childhood maltreatment: A guide to taking action and generating evidence. France: WHO Library Cataloguing-in-Publication Data. 
Wright, K. D., Asmundson, G. J., McCreary, D. R., Scher, C., Hami, S., \& Stein, M. B. (2001). Factorial validity of the childhood trauma questionnaire in men and women. Depression and Anxiety,13(4), 179-183.

Yanos, P. T., Czaja, S. J., \& Widom, C. S. (2010). A prospective examination of service use by abused and neglected children followed up into adulthood. Psychiatric Services (Washington, D.C.),61(8), 796-802. doi:10.1176/appi.ps.61.8.796

Young, T. K., \& Katz, A. (1998). Survivors of sexual abuse: Clinical, lifestyle and reproductive consequences. CMAJ : Canadian Medical Association Journal = Journal De l'Association Medicale Canadienne, 159(4), 329-334. 